\title{
Resistencia química del hormigón XXVI. Influencia de la adición de escoria a un cemento portland. Estudio de la concentración iónica (del sistema cemento 3/escoria-agua) de mar artificial
}

\author{
DEMETRIO GASPAR-TEBAR Y JOSE LUIS SAGRERA-MORENO
}

IETCC-CSIC

\begin{abstract}
RESUMEN
En el presente trabajo, continuación de otros, se estudia la evolución de la cantidad de nueva fase sólida formada en el agua de mar artificial ASTM D 1141-75 en donde han estado sumergidas las series de probetas de mortero (1:3) hechas con cemento portland (cemento 3/escoria $=85 / 15-65 / 35-40 / 60$ y $30 / 70$, en peso, durante 56-90-180 y 360 dias (períodos de conservación-ataque), en esta etapa, después del periodo de curado (1 dia en cámara húmeda y 21 dias bajo agua potable filtrada). Asi mismo, se estudia la variación del $\mathrm{pH}$ y de la concentración de iones $\mathrm{Ca}(\mathrm{II}), \mathrm{Mg}$ (II), $\mathrm{SO}_{4}$ (II) y $\mathrm{Cl}$ (I) de dicha agua de mar artificial ASTM, asi como del contenido de iones $\mathrm{Ca}$ (II), $\mathrm{Mg}$ (II) y $\mathrm{SO}_{4}$ (II) de las mencionadas nuevas fases sólidas formadas.
\end{abstract}

En los casos estudiados se ha puesto de manifiesto que en la disolución se ha producido un aumento de la concentración de $\mathrm{Ca}$ (II) y del valor del $\mathrm{pH}$, una disminución del contenido de $\mathrm{Mg}$ (II), $\mathrm{SO}_{4}$ (II) y $\mathrm{Cl}$ (I), asi como la formación de una nueva fase sólida que son función de la mezcla utilizada para fabricar las mencionadas series de probetas y del tiempo de conservación-ataque. Por otra parte, se ha probado que la evolución de los contenidos de $\mathrm{Ca}$ (II) y de $\mathrm{Mg}$ (II) están intimamente ligados; cuando los del primero aumentan, los del segundo disminuyen y viceversa, existiendo un punto que corresponde al equilibrio iónico $\mathrm{Ca}(I I) \rightleftharpoons \mathrm{Mg}(\mathrm{II})$.

Las cantidades de $\mathrm{Ca}$ (II) en la disolución y en la nueva fase sólida, que proceden de los compuestos disueltos del cemento hidratado experimentan un incremento según lo hace el tiempo de conservación-ataque de cada serie de probetas fabricadas con una mezcla cemento $3 /$ escoria y disminuyen exponencialmente conforme lo hace el contenido de $\mathrm{Ca}$ (II) en el agua de mar artificial ASTM, el proceso de disolución de los compuestos de $\mathrm{Ca}$ (II) del cemento (valores medios) es aditivo.

El ion $\mathrm{Mg}$ (II) ha desaparecido, prácticamente, del agua de mar artificial ASTM en donde han estado sumergidas las series de probetas de mortero hechas con cemento $3 y$ con la mezcla que tiene $15 \%$ de escoria, en peso; en estos medios ha precipitado en parte, como brucita. En los medios restantes se encuentra, dicho ion, en cantidades diversas, según la mezcla y el tiempo de conservación-ataque.

Los contenidos de $\mathrm{SO}_{4}$ (II) y $\mathrm{Cl}$ (I) del agua de mar artificial experimentan una disminución que depende de la mezcla cemento 3/escoria utilizada para fabricar las series de probetas de mortero. Las mayores cantidades desaparecidas corresponden a los medios en donde han estado las probetas de mortero hechas con cemento 3 y con las mezclas que tienen 15 y $35 \%$, en peso, de escoria para los iones $\mathrm{SO}_{4}$ (II) y con las mezclas con $35-60$ y $70 \%$, en peso, de escoria para los iones $\mathrm{Cl}(\mathrm{I})$.

\section{SUMMARY}

This work, which is a follow-up of others, studies the development of the solid-stage quantity formed in ASTM $D$ 1141-75 artificial seawater, in which the series of samples of mortar (1:3), made up of a portland cement (cement $3<>P-450$ ) and the mixtures cement $3 / \mathrm{slag}=$ $=85 / 15-65 / 35-40 / 60$ and $30 / 70$, in weight, were submerged during $56-90-180$ and 360 days (periods of conservation-attack) in this stage, after the curing period (1 day in a curing chamber and 21 days under drinking filtered water). The changes in the $\mathrm{pH}$ value and the concentration of $\mathrm{Ca}(\mathrm{II}), \mathrm{Mg}(\mathrm{II}), \mathrm{SO}_{4}$ (II) and $\mathrm{Cl}(\mathrm{I})$ ions in this ASTM artificial sea-water are likewise studied, so as the content of $\mathrm{Ca}$ (II), $\mathrm{Mg}$ (II) and $\mathrm{SO}_{4}$ (II) ions of the new solid phase formed.

In the studied cases it has been shown that an increase of $\mathrm{Ca}$ (II) in the solution and of the $\mathrm{pH}$ value is produced, the $\mathrm{Mg}(\mathrm{II}), \mathrm{SO}_{4}(\mathrm{II})$ and $\mathrm{Cl}(\mathrm{I})$ content is reduced and a solid phase is formed, these being a function of the mixture used for making the series of samples mentioned and of the conservation-attack period. Furthermore, it has been proved that the evolution in the $\mathrm{Ca}$ (II) and $\mathrm{Mg}$ (II) content is closely linked: when it increases in the first one, that of the second decreases and vice versa, being there a point which corresponds to the $\mathrm{Ca}(\mathrm{II}) \rightleftharpoons \mathrm{Mg}$ (II) ionic equilibrium.

Quantities of $\mathrm{Ca}$ (II) into the solution and in the new solid phase, from the compounds of hydrated cement, show an increase, in accordance with the conservation-attack period of each serie of samples made up with a cement $3 /$ slag mixture, and decrease sharply in accordance with the reduction of cement 3 content in the mixture. If moreover the $\mathrm{Ca}$ (II) content in the ASTM artificial sea-water is taken into account, the dissolving process of the $\mathrm{Ca}$ (II) compounds of the cement (average values) may be added.

The $\mathrm{Mg}$ (II) ion has practically disappeared from the artificial sea-water where the series of mortar samples made up of cement 3 and the mixture which has $15 \%$ slag in weight, have been submerged; in these means it has precipitated, in a part, as brucite. In the other means this ion is found in diverse quantities, according to the mixture and to the conservation-attack time.

The content of $\mathrm{SO}_{4}(I I)$ and $\mathrm{Cl}(I)$ in the artificial sea-water has, in likewise experience, a decrease which depends on the mixture used in the manufacture of the mortar samples and the time of conservation-attack. The greatest quantities that have disappeared correspond to the means containing the mortar samples made with cement 3 and the mixtures with $15 \%$ and $35 \%$ slag, in weight, for the $\mathrm{SO}_{4}$ (II) ions and the mixtures with $35 \%, 60 \%$ and $70 \%$ slag for the $\mathrm{Cl}(\mathrm{I})$ ions. 


\section{INTRODUCCION}

En otros trabajos anteriores (1) (2) (3) (4) se estudió:

a) La evolución que experimenta la resistencia química por el método de Koch-Steinegger y las modificaciones sufridas por las resistencias mecánicas a flexotracción de las probetas de mortero (1:3) de $1 \times 1 \times 6 \mathrm{~cm}$ hechas con el cemento portland (cemento $3<>$ P-450), objeto del presente artículo, y con las mezclas cemento $3 /$ escoria $=85 / 15$ - 65/35 $40 / 60$ y $30 / 70$, en peso, sumergidas en agua potable filtrada $\left(^{\star}\right)$, unas series de 12 probetas, y en agua de mar artificial ASTM D 1141-75 (**), otras series análogas de 12 probetas, durante 56 - 90 - 180 y 360 días, en esta etapa, después de haberlas curado 24 horas en un recinto saturado de humedad y, a continuación, bajo agua potable filtrada durante 21 dias (1).

b) La composición estructural de las nuevas fases sólidas formadas en los medios de curado y de conservación (agua potable filtrada) (2), así como de conservaciónataque (agua de mar artificial ASTM) (3), en donde las mencionadas series de probetas han estado sumergidas.

c) La evolución de las características estructurales de la fracción enriquecida (cemento 3 hidratado e hidratado-atacado) extraída de uno de los prismas de cada serie de probetas de mortero de los sistemas mencionados anteriormente (2) (3).

d) La variación de la concentración de los iones calcio y sulfato en los medios de curado y de conservación (agua potable filtrada), en donde han estado sumergidas las diversas series de probetas de mortero, así como de las fases sólidas formadas, y la evolución del $\mathrm{pH}$ de dichos medios (4).

En el presente artículo, continuación de los anteriores y que se ampliará con otros, se estudia la variación de la concentración de los iones calcio, magnesio, sulfato y cloruro del agua de mar artificial (ASTM D 1141-75) en donde han estado sumergidas diversas series de probetas de mortero, así como de las fases sólidas formadas (los tres primeros); así mismo, se estudia la variación del $\mathrm{pH}$ de dichos medios y de las cantidades de las nuevas fases sólidas.

$\left.{ }^{\star}\right)$ Sistema: cemento 3/escoria-agua potable filtrada. $\left.{ }^{\star \star}\right)$ Sistema: cemento $3 /$ escoria-agua de mar artificial.

\section{PARTE EXPERIMENTAL}

En el agua de mar artificial (ASTM D 1141-75) en donde han estado sumergidas las distintas series de probetas de mortero $(1: 3)$ hechas con cemento 3 y con las mezclas cemento $3 /$ escoria $=85 / 15-65 / 35-40 / 60$ y $30 / 70$ (en peso), una vez separada la nueva fase sólida formada como se señaló en (5), se ha determinado el contenido de los iones $\mathrm{Ca}$ (II) y $\mathrm{Mg}$ (II) complexométricamente con EDTA, el de los iones $\mathrm{SO}_{4}$ (II) gravimétricamente al estado de sulfato de bario, el de los iones $\mathrm{Cl}$ (I) volumétricamente por el método de Mohr y el valor del $\mathrm{pH}$ por medio de un $\mathrm{pH}$-metro, marca Crison, modelo 501. Cada serie de probetas de mortero se ha sumergido, después de curadas como se ha señalado en el apartado anterior, en $800 \mathrm{ml}$ de agua de mar artificial ASTM durante 56 - 90 - 180 y 360 días (períodos de conservación-ataque).

En la nueva fase sólida, una vez separada (5) y puesta en disolución por ataque con una disolución de ácido clorhídrico $(1+1)$, se ha determinado el contenido de los iones $\mathrm{Ca}$ (II), $\mathrm{Mg}$ (II) y $\mathrm{SO}_{4}$ (II).

De los materiales utilizados (cemento 3 , escoria, arena, agua de mar artificial y agua potabable filtrada) y características, de la técnica operatoria seguida para preparar las mezclas cemento 3/escoria, así como para curar y conservar las probetas de mortero (1:3) de las diversas series en agua potable filtrada y en agua de mar artificial se dio cuenta en (1).

\section{RESULTADOS Y DISCUSION}

En la tabla 1 se encuentran las cantidades de las nuevas fases sólidas formadas en los medios (agua de mar artificial ASTM D 1141-75) en donde han estado sumergidas las diversas series de probetas de mortero hechas con cemento 3 y con las mezclas cemento 3/escoria $=85 / 15-65 / 35-40 / 60$ y $30 / 70$ (en peso), durante 56 - 90 - 180 y 360 días, así como los compuestos cristalinos identificados por DRX, los valores del $\mathrm{pH}$ y las cantidades de $\mathrm{Ca}$ (II), $\mathrm{Mg}$ (II), $\mathrm{SO}_{4}$ (II) y $\mathrm{Cl}$ (I) en dichos medios. Ademas, se incluyen los contenidos de $\mathrm{Ca}$ (II), $\mathrm{Mg}$ (II) y $\mathrm{SO}_{4}$ (II) de las mencionadas fases sólidas.

En las figuras 1 a 11 , que se discuten en los apartados siguientes, se han representado dichos valores en función de la edad (tiempo de conservación-ataque) y de la mezcla cemento 3/escoria utilizada para fabricar las mencionadas series de probetas de mortero. 
TABLA 1

Sistema: cemento 3/escoria-agua de mar artificial ASTM

Evolución de la fase sólida formada, del $\mathrm{pH}$ y de los contenidos de $\mathrm{Ca}$ (II), $\mathrm{Mg}$ (II), $\mathrm{SO}_{4}$ (II) y $\mathrm{Cl}$ (I) Agua de mar ASTM (D 1141-75); contenidos en $800 \mathrm{ml}$ de:

$$
\begin{aligned}
& \mathrm{Ca} \text { (II) }=1,04 \times 10^{-2} \text { moles } \\
& \mathrm{Mg} \text { (II) }=4,43 \times 10^{-2} \text { moles } \\
& \mathrm{SO}_{4} \text { (II) }=2,44 \times 10^{-2} \text { moles } \\
& \mathrm{Cl}\left(\text { I) }=44,2 \times 10^{-2} \text { moles, } \mathrm{y}\right. \\
& \mathrm{pH}=6,5
\end{aligned}
$$

\begin{tabular}{|c|c|c|c|c|c|c|c|c|c|c|c|c|c|c|}
\hline \multirow{2}{*}{$\begin{array}{l}\text { Mezcla } \\
\text { cemen- } \\
\text { to } 3\end{array}$} & \multirow{2}{*}{$\begin{array}{l}\text { Edad } \\
\text { dias }\end{array}$} & \multicolumn{2}{|c|}{ Fase sólida } & \multirow{2}{*}{$\begin{array}{c}\text { Diso- } \\
\text { luclón } \\
\text { pH }\end{array}$} & \multicolumn{3}{|c|}{ Ca (II); moles $\times 10^{-2}$} & \multicolumn{3}{|c|}{ Mg (II); moles $\times 10^{-2}$} & \multicolumn{3}{|c|}{$\mathrm{SO}_{4}(\mathrm{II}) ;$ moles $\times 10^{-2}$} & \multirow{2}{*}{$\begin{array}{c}\text { Cl (I); } \\
\text { moles } \times \\
\times 10^{-2} \\
\text { Diso- } \\
\text { lución }\end{array}$} \\
\hline & & $\mathbf{g}$ & DRX & & $\begin{array}{c}\text { Diso- } \\
\text { lución }\end{array}$ & $\begin{array}{c}\text { Fase } \\
\text { sólida }\end{array}$ & Suma & $\begin{array}{l}\text { Diso- } \\
\text { lución }\end{array}$ & $\begin{array}{l}\text { Fase } \\
\text { sólida }\end{array}$ & Suma & $\begin{array}{l}\text { Diso- } \\
\text { lución }\end{array}$ & $\mid \begin{array}{c}\text { Fase } \\
\text { sólida }\end{array}$ & Suma & \\
\hline $100 / 0$ & $\begin{array}{r}56 \\
90 \\
180 \\
360\end{array}$ & $\begin{array}{l}1,35 \\
1,57 \\
1,79 \\
4,35\end{array}$ & $\begin{array}{l}\mathrm{Cc} \uparrow-\mathrm{Ag}-\mathrm{B} \uparrow \\
\mathrm{Cc} \uparrow-\mathrm{Ag}-\mathrm{B} \uparrow \\
\mathrm{Cc} \uparrow-\mathrm{Ag}-\mathrm{B} \uparrow \\
\mathrm{Cc} \uparrow-\mathrm{Ag}-\mathrm{B} \uparrow\end{array}$ & $\begin{array}{c}11,8 \\
a \\
12,5\end{array}$ & $\begin{array}{l}3,86 \\
4,59 \\
4,48 \\
3,29\end{array}$ & $\begin{array}{l}1,13 \\
1,17 \\
1,52 \\
3,39\end{array}$ & $\begin{array}{l}4,99 \\
5,76 \\
6,00 \\
6,68\end{array}$ & $\begin{array}{l}\text { n.d. } \\
\text { n.d. } \\
\text { n.d. } \\
\text { n.d. }\end{array}$ & $\begin{array}{l}0,22 \\
0,45 \\
0,27 \\
0,43\end{array}$ & $\begin{array}{l}0,22 \\
0,45 \\
0,27 \\
0,43\end{array}$ & \begin{tabular}{l|l|}
1,39 \\
1,33 \\
1,11 \\
0,76
\end{tabular} & $\begin{array}{l}0,03 \\
0,03 \\
0,03 \\
0,04\end{array}$ & $\begin{array}{l}1,42 \\
1,36 \\
1,14 \\
0,80\end{array}$ & $\begin{array}{l}42,74 \\
43,70 \\
44,10 \\
44,18\end{array}$ \\
\hline $85 / 15$ & $\begin{array}{r}56 \\
90 \\
180 \\
360\end{array}$ & $\begin{array}{l}0,85 \\
1,07 \\
1,42 \\
3,15\end{array}$ & $\begin{array}{l}\text { Cct-Ag-B } \\
\text { Cc }-A g-B \\
\text { Cc } \uparrow-A g-B \\
C c \uparrow-A g-B\end{array}$ & $\begin{array}{c}11,7 \\
a \\
12,0\end{array}$ & $\begin{array}{l}3,57 \\
3,28 \\
3,65 \\
3,05\end{array}$ & $\begin{array}{l}0,58 \\
0,94 \\
1,31 \\
2,87\end{array}$ & $\begin{array}{l}4,15 \\
4,22 \\
4,96 \\
5,92\end{array}$ & \begin{tabular}{c|} 
n.d. \\
0,01 \\
n.d. \\
0,18
\end{tabular} & $\begin{array}{l}0,19 \\
0,09 \\
0,15 \\
0,07\end{array}$ & $\begin{array}{l}0,19 \\
0,10 \\
0,15 \\
0,25\end{array}$ & \begin{tabular}{l|l|}
1,51 \\
1,35 \\
1,07 \\
0,77
\end{tabular} & $\begin{array}{c}0,02 \\
- \\
0,03 \\
0,05\end{array}$ & $\begin{array}{l}1,53 \\
1,35 \\
1,10 \\
0,82\end{array}$ & $\begin{array}{l}40,72 \\
42,72 \\
42,74 \\
44,10\end{array}$ \\
\hline $65 / 35$ & $\begin{array}{r}56 \\
90 \\
180 \\
360\end{array}$ & $\begin{array}{l}0,31 \\
0,86 \\
1,22 \\
1,77\end{array}$ & $\begin{array}{l}\mathrm{Cc}-\mathrm{Ag} \uparrow \\
\mathrm{Cc}-\mathrm{Ag} \\
\mathrm{Cc} \uparrow \simeq \mathrm{Ag} \\
\mathrm{C} \uparrow \uparrow \mathrm{Ag}\end{array}$ & $\begin{array}{c}7,5 \\
a \\
10\end{array}$ & $\begin{array}{l}2,30 \\
2,61 \\
2,64 \\
2,75\end{array}$ & $\begin{array}{l}0,27 \\
0,70 \\
1,11 \\
1,55\end{array}$ & $\begin{array}{l}2,57 \\
3,31 \\
3,75 \\
4,30\end{array}$ & $\begin{array}{l}0,50 \\
0,11 \\
0,08 \\
0,16\end{array}$ & \begin{tabular}{c|} 
n.d. \\
0,04 \\
0,02 \\
0,03
\end{tabular} & $\begin{array}{l}0,50 \\
0,15 \\
0,10 \\
0,19\end{array}$ & \begin{tabular}{l|l|}
1,70 \\
1,57 \\
1,51 \\
1,56
\end{tabular} & $\begin{array}{l}\text { ind. } \\
0,01 \\
0,02 \\
0,03\end{array}$ & $\begin{array}{l}1,70 \\
1,58 \\
1,53 \\
1,59\end{array}$ & $\begin{array}{l}38,85 \\
41,34 \\
41,24 \\
44,06\end{array}$ \\
\hline $40 / 60$ & $\begin{array}{r}56 \\
90 \\
180 \\
360\end{array}$ & $\begin{array}{l}0,27 \\
0,47 \\
0,75 \\
1,46\end{array}$ & $\begin{array}{l}\text { Cc-Ag } \uparrow \\
\text { Cc-Ag } \uparrow \\
\text { Cc-Ag } \uparrow \\
\text { Cc-Ag }{ }^{\dagger}\end{array}$ & $\begin{array}{c}7,8 \\
a \\
8,3\end{array}$ & $\begin{array}{l}1,49 \\
1,44 \\
1,42 \\
1,33\end{array}$ & $\begin{array}{l}0,24 \\
0,37 \\
0,65 \\
0,80\end{array}$ & $\begin{array}{l}1,73 \\
1,81 \\
2,07 \\
2,13\end{array}$ & $\begin{array}{l}2,03 \\
2,05 \\
2,05 \\
2,30\end{array}$ & \begin{tabular}{l|} 
n.d. \\
0,05 \\
0,04 \\
0,10
\end{tabular} & $\begin{array}{l}2,03 \\
2,10 \\
2,09 \\
2,40\end{array}$ & $\begin{array}{l}2,10 \\
2,08 \\
1,99 \\
2,13\end{array}$ & $\begin{array}{l}\text { ind. } \\
\text { ind. } \\
\text { ind. } \\
\text { ind. }\end{array}$ & $\begin{array}{l}2,10 \\
2,08 \\
1,99 \\
2,13\end{array}$ & $\begin{array}{l}39,63 \\
41,50 \\
40,86 \\
44,00\end{array}$ \\
\hline $30 / 70$ & $\begin{array}{r}56 \\
90 \\
180 \\
360\end{array}$ & $\begin{array}{l}0,23 \\
0,41 \\
0,71 \\
1,19\end{array}$ & $\begin{array}{l}\text { Cc-Ag }{ }^{\dagger} \\
\text { Cc-Ag }{ }^{\dagger} \\
\text { Cc-Ag }{ }^{\dagger} \\
\text { Cc-Ag }{ }^{\dagger}\end{array}$ & $\begin{array}{c}7,5 \\
a \\
8,5\end{array}$ & $\begin{array}{l}1,52 \\
1,34 \\
1,04 \\
1,07\end{array}$ & $\begin{array}{l}0,19 \\
0,36 \\
0,64 \\
0,89\end{array}$ & $\begin{array}{l}1,71 \\
1,70 \\
1,68 \\
1,96\end{array}$ & \begin{tabular}{l|}
2,66 \\
2,51 \\
2,35 \\
2,43
\end{tabular} & \begin{tabular}{|c|} 
n.d. \\
0,01 \\
0,02 \\
0,10
\end{tabular} & $\begin{array}{l}2,66 \\
2,52 \\
2,37 \\
2,53\end{array}$ & $\begin{array}{l}2,33 \\
2,25 \\
2,25 \\
2,23\end{array}$ & $\begin{array}{c}0,01 \\
\text { n.d. } \\
\text { ind. } \\
\text { n.d. }\end{array}$ & $\begin{array}{l}2,34 \\
2,25 \\
2,25 \\
2,23\end{array}$ & $\begin{array}{l}40,56 \\
42,07 \\
41,23 \\
43,29\end{array}$ \\
\hline
\end{tabular}

\subsection{Evolución de la cantidad de fase só- lida}

En las figuras 1 y 2 se ha representado la cantidad de fase sólida formada en los medios mencionados anteriormente en donde han estado sumergidas las series de probetas hechas con una misma mezcla, en función del tiempo de conservación-ataque, en la primera, y de la edad de conservación-ataque para cada mezcla utilizada en la fabricación de las distintas series de probetas, en la segunda, en las que se puede apreciar que dicha cantidad de fase sólida es:

a) función del tiempo de conservación-ataque para cada mezcla. Dicha cantidad de fase sólida aumenta conforme lo hace la edad (figura 1) y la cantidad de cemento 3 en la mezcla.

b) función de la mezcla utilizada en la fabricación de las probetas de mortero, disminuyendo para cada edad conforme lo hace la cantidad de cemento en dicha mezcla (figura 2).

En la mencionada fase sólida, que en ciertos casos se encuentra impurificada por pequeñas fracciones desprendidas de las probetas, se han identificado por difracción de rayos $X(3)$ los picos de los compuestos cristalinos calcita, aragonito y brucita. 


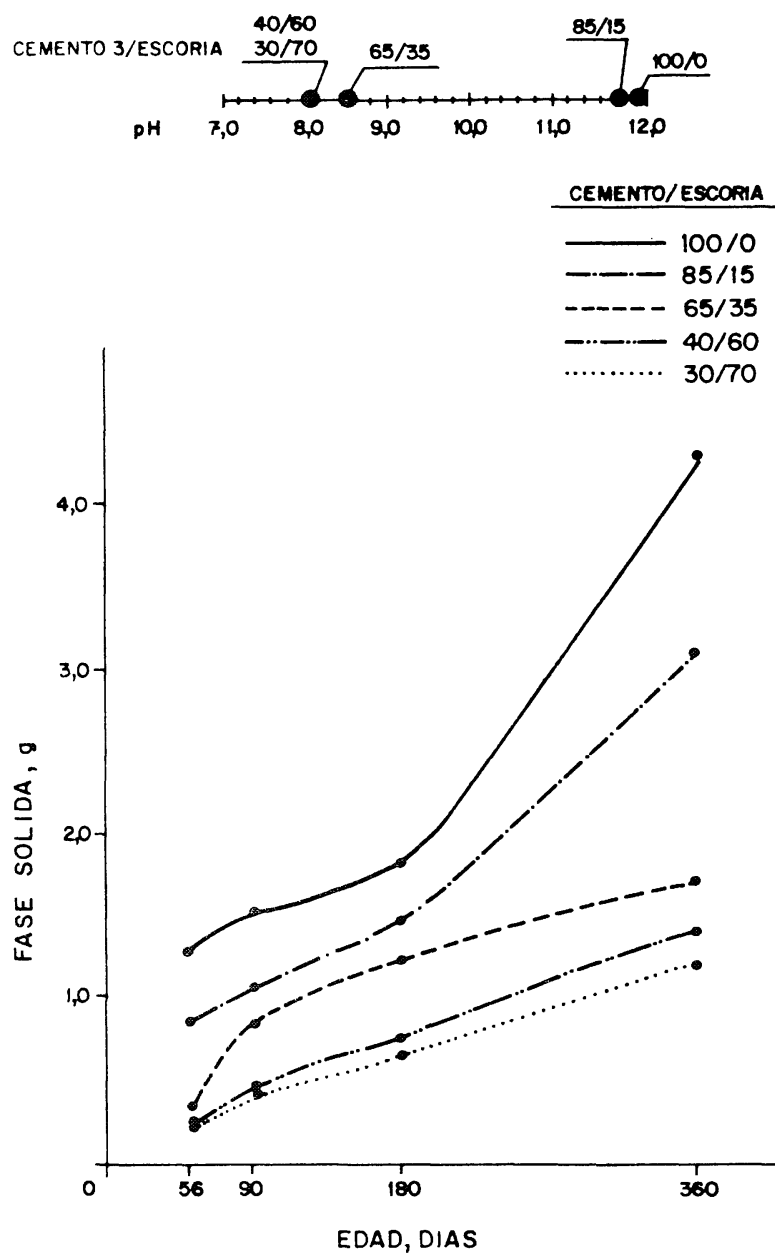

Fig. 1.-Sistema: cemento 3/escoria - agua de mar artificial ASTM. Evolución de la cantidad de fase sólida y del $\mathrm{pH}$.

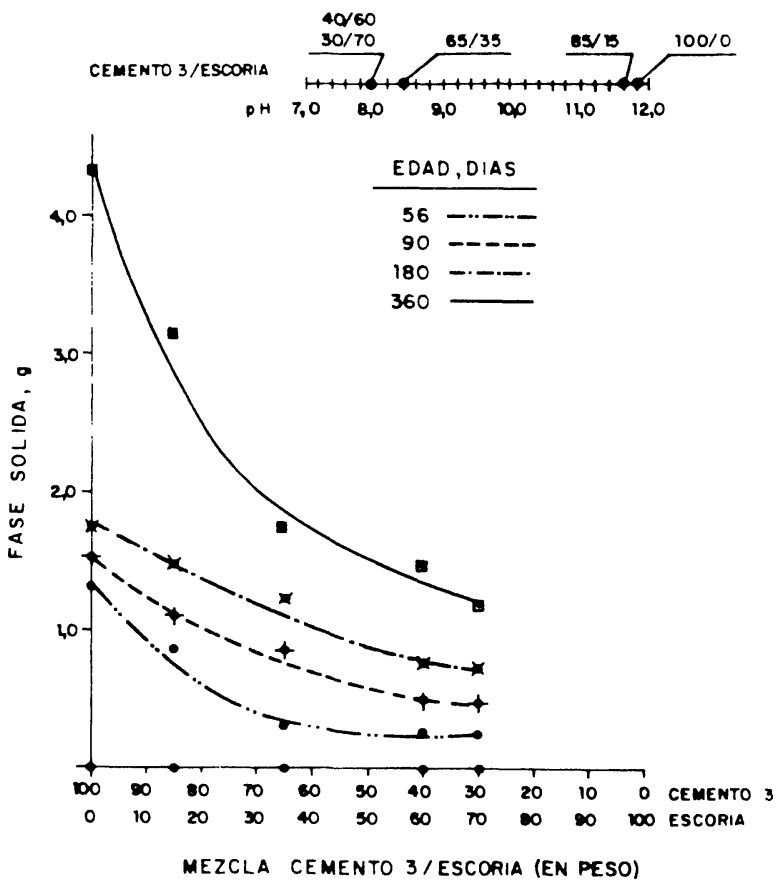

Fig. 2.- Sistema: cemento 3/escoria - agua de mar artificial ASTM. Evolución de la cantidad de fase sólida y del $\mathrm{pH}$.
Los picos de la calcita y del aragonito, con intensidad variable, se han detectado en todos los DRX y los de la brucita, sólamente, en las fases sólidas formadas en el agua de mar artificial en donde han estado sumergidas las series de probetas de mortero hechas con cemento 3 , con la máxima intensidad, y con la mezcla que tiene el $15 \%$ de escoria (en peso), con la mínima intensidad.

La máxima intensidad de los picos de la calcita, análoga entre si, corresponde a los DRX de las fases sólidas que se han formado en los medios de conservación-ataque (agua de mar artificial) en donde han estado sumergidas, durante las cuatro edades, las diversas series de probetas de mortero fabricadas con cemento 3 y con las mezclas cemento 3/escoria $=85 / 15$ (en peso), para todas las edades, $y$ $65 / 35$ (en peso), para $t=22+180$ días y 22 + 360 dias; la mínima intensidad corresponde a los diagramas de las fases sólidas que aparecen en el agua de mar artificial en donde se han conservado las probetas hechas con las mezclas cemento $3 /$ escoria $=65 / 35$ (en peso), para $t=22+56$ y $22+90$ días, $40 / 60$ y $30 / 70$ (en peso), para todas las edades. Por el contrario, la máxima intensidad de los picos del aragonito se encuentra en los DRX que presentan la mínima intensidad para los picos de la calcita y viceversa.

\subsection{Evolución del pH}

El pH del agua de mar artificial ASTM D 1141$75(6,5)$ ha experimentado un incremento en todos los casos, encontrándose comprendido en los entornos 11,8 a $12,5-11,7$ a $12,0-7,5$ a 10 y 7,5 a 8,5 según se trate de los medios en donde han estado las series de probetas hechas con las mezclas cemento $3 /$ escoria $=$ $=100 / 0$ (en peso) el primero, 85/15 (en peso) el segundo, 65/35 (en peso) el tercero, 40/60 y $30 / 70$ (en peso) el cuarto (figs. 1 y 2 ).

\subsection{Evolución del contenido de $\mathrm{Ca}$ (II)}

En las figuras 3 y 4 se ha representado el contenido de $\mathrm{Ca}$ (II) disuelto [Ca (II) en la fase líquida + $\mathrm{Ca}$ (II) en la fase sólida] - procedente, de un modo especial, del $\mathrm{Ca}(\mathrm{OH})_{2}$ del cemento hidratado- en función del tiempo de conservación-ataque para las diversas series de probetas de mortero hechas con cada una de las mezclas cemento $3 /$ escoria estudiadas, en la primera figura, y en función de la mezcla utilizada para fabricar las diversas series de probetas de mortero para cada edad (tiempo de conservación-ataque), en la segunda.

En la figura 3 se aprecia que la cantidad de dicho $\mathrm{Ca}$ (II) disuelto, para cada mezcla, au- 
menta con el tiempo de conservación-ataque; los mayores incrementos experimentados por las diversas series de probetas de mortero sumergidas durante 56 y 360 días $\left(1,69 \times 10^{-2}\right.$ $1,77 \times 10^{-2}$ y $1,73 \times 10^{-2}$ moles) y los menores $\left(0,40 \times 10^{-2}\right.$ y $\left.0,25 \times 10^{-2}\right)$ corresponden a los medios en donde han estado las diversas series de probetas de mortero hechas con cemento 3 y con las mezclas que tienen los menores contenidos de escoria (15 y $35 \%$ de escoria, en peso) los primeros y con los mayores contenidos de escoria (60 y $70 \%$ en peso) los segundos.

En la figura 4 se observa que, para cada edad, la cantidad de $\mathrm{Ca}$ (II) $<>\mathrm{Ca}(\mathrm{OH})_{2}$ disuelto, que se encuentra en la disolución y en la fase sólida, disminuye bruscamente conforme lo hace el contenido de cemento 3 en la mezcla cemento 3/escoria utilizada para fabricar las diversas series de probetas de mortero. Si además del mencionado $\mathrm{Ca}$ (II) se considera el $\mathrm{Ca}$ (II) que existe en el agua de mar artificial ASTM $\left(1,04 \times 10^{-2}\right.$ moles $\left./ 800 \mathrm{ml}\right)$, es decir, el

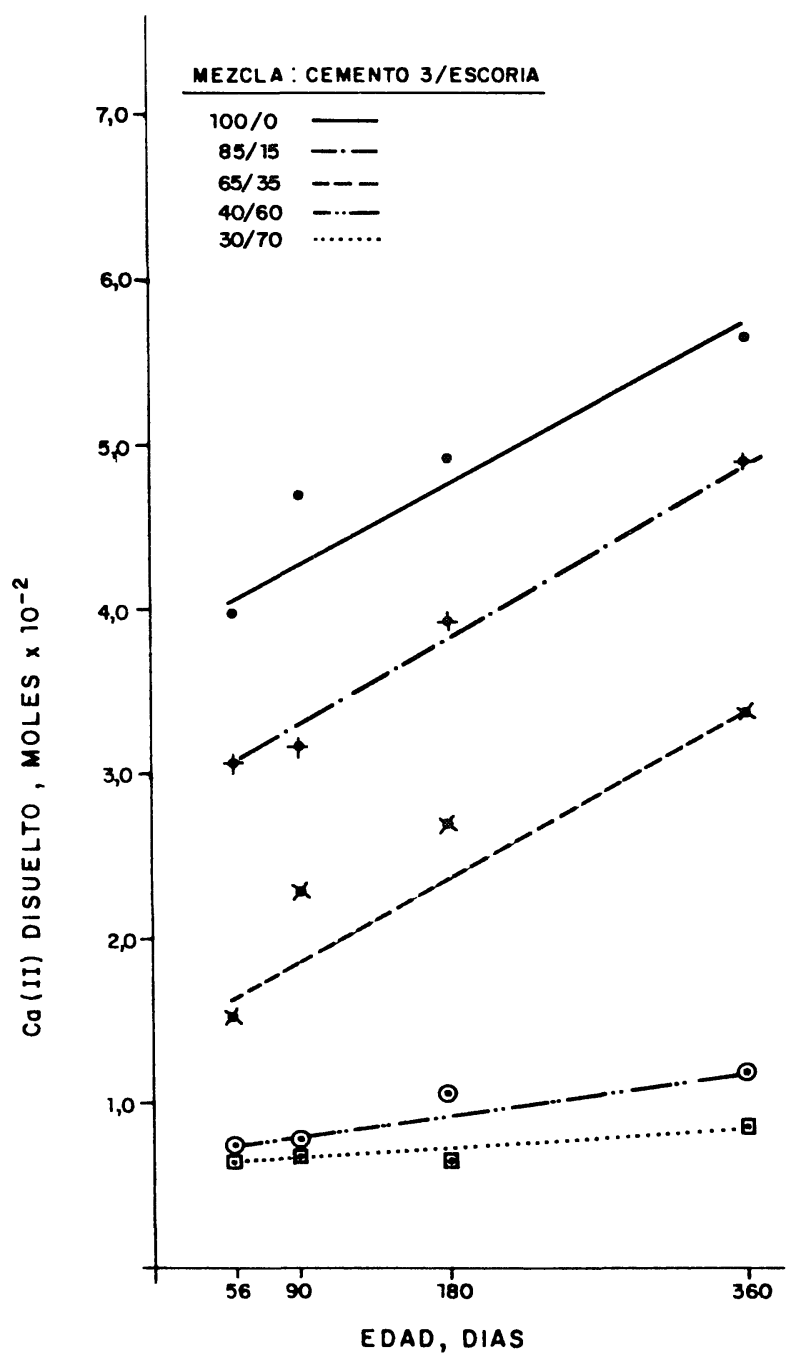

Fig. 3.-Sistema: cemento 3/escoria - agua de mar artificial ASTM. Evolución del contenido de Ca (II) disuelto.

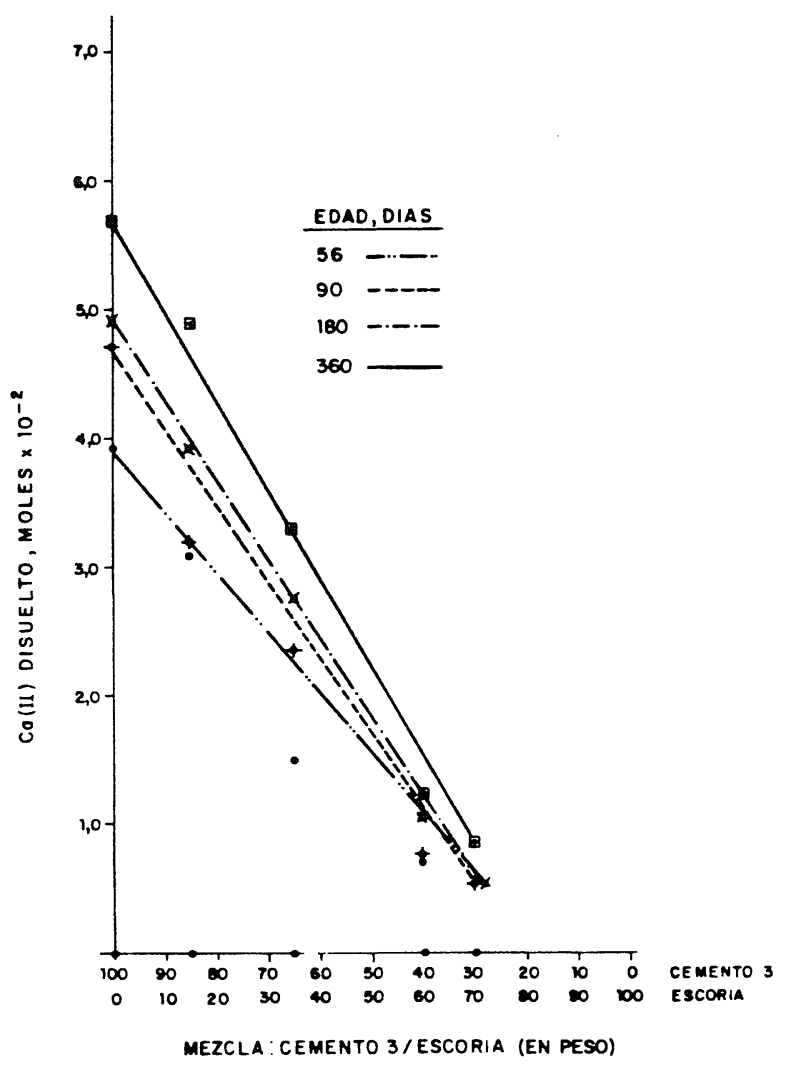

Fig. 4.-Sistema: cemento 3/escoria - agua de mar artificial ASTM. Evolución del contenido de Ca (II) disuelto.

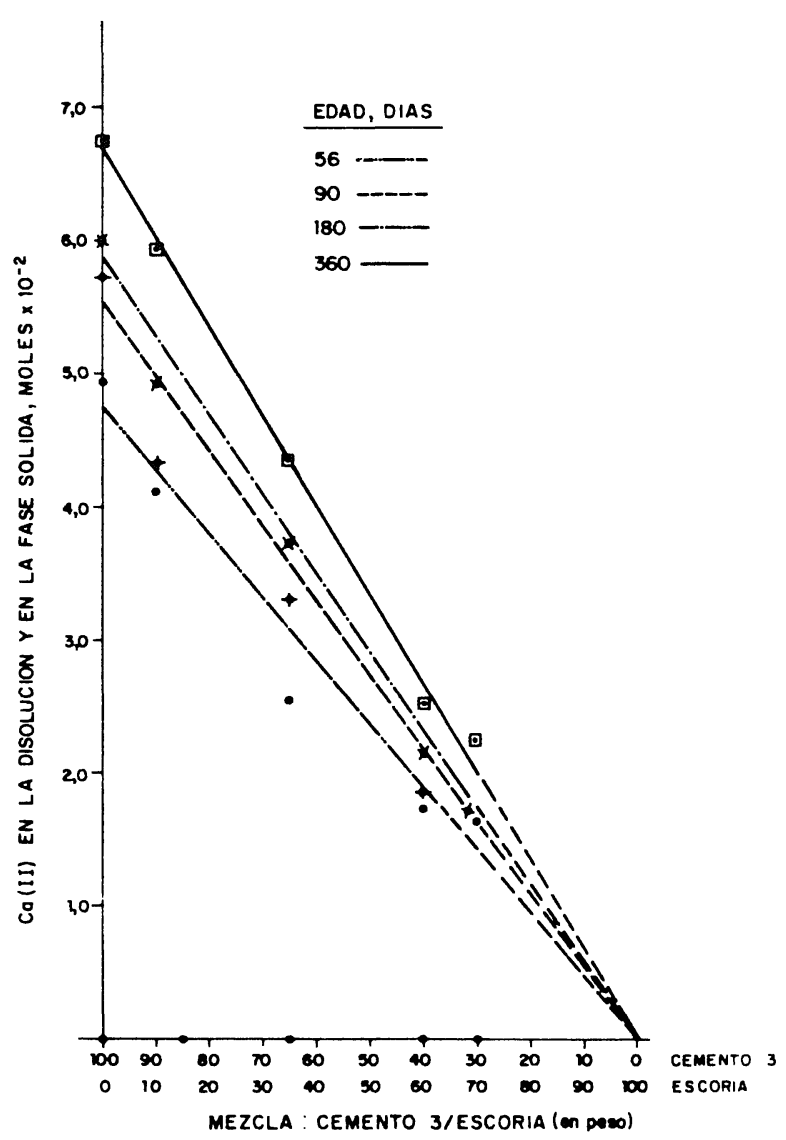

Fig. 5.-Sistema: cemento 3/escoria - agua de mar artificial ASTM. Evolución del contenido de $\mathrm{Ca}$ (II) total. 
Ca (II) total que existe en la disolución y el $\mathrm{Ca}$ (II) que se encuentra en la fase sólida (figura 5), se aprecia que, para cada edad, dichas cantidades se encuentran alineadas, prácticamente, en una recta que une los puntos correspondientes al $\mathrm{Ca}(\mathrm{OH})_{2}$ disuelto de las series de probetas hechas con cemento 3 sin adición de escoria, más el del agua de mar, en ordenadas, y el de la mezcla teórica cemento $3 /$ escoria $=0 / 100$, es decir cuando no existe cemento 3 , en abscisas.

\subsection{Evolución del contenido de Mg (II)}

En las figuras 6 y 7 se ha representado el contenido de $\mathrm{Mg}$ (II) en el agua de mar artificial (ASTM D 1141-75), en donde han estado sumergidas las diversas series de probetas de mortero, junto con el correspondiente a las nuevas fases sólidas que se han formado en dichos medios, en función de la edad (primera figura) y de la mezcla cemento 3/escoria utilizada para fabricar dichas series de probetas (segunda figura).

El contenido de $\mathrm{Mg}$ (II) del agua de mar artificial $\left(4,43 \times 10^{-2}\right.$ moles/800 $\left.\mathrm{ml}\right)$ experimenta, en todos los casos estudiados, una disminución que es función del tiempo de conservación-ataque y, de un modo especial, de la mezcla utilizada en la fabricación de las diversas series de probetas de mortero (figuras 6 y 7 ); hecho que influye en las condiciones del medio modificando, de un modo especial, la concentración de los grupos $\mathrm{OH}(\mathrm{I})$, es decir, el valor del $\mathrm{pH}$.

El ion $\mathrm{Mg}$ (II) ha desaparecido, prácticamente, de los medios (agua de mar artificial ASTM) en donde han estado sumergidas las series de probetas de mortero hechas con cemento $3 \mathrm{y}$ con la mezcla que tiene el $15 \%$, en peso, de escoria, en donde se ha encontrado en cantidades menores de $0,2 \times 10^{-2}$ moles, en el caso de la segunda mezcla, para las edades de $22+90$ y $22+360$ días; en los casos restantes no se ha detectado. En los medios correspondientes a las series de probetas elaboradas con la mezcla cemento 3 /escoria = $=65 / 35$ (en peso), dicho ion se ha encontrado en cantidades inferiores a 0,6 $\times 10^{-2}$ moles, mientras que en aquellos en donde han estado las series de probetas fabricadas con las mezclas que tienen los mayores contenidos de escoria (60 y $70 \%$, en peso) se ha encontrado en cantidades superiores a $2 \times 10^{-2}$ moles.

Por otra parte, el ion Mg (II) se ha encontrado en las nuevas fases sólidas formadas en el agua de mar artificial en donde han estado sumergidas las distintas series de probetas de mortero hechas con cemento 3 y con la mezcla cemento $3 /$ escoria $=85 / 15$, en peso, (en cantidades comprendidas entre $0,22 \times 10^{-2}$ moles y $0,45 \times 10^{-2}$ moles, en el primer caso, y $0,07 \times 10^{-2}$ moles y $0,19 \times 10^{-2}$ moles, en el

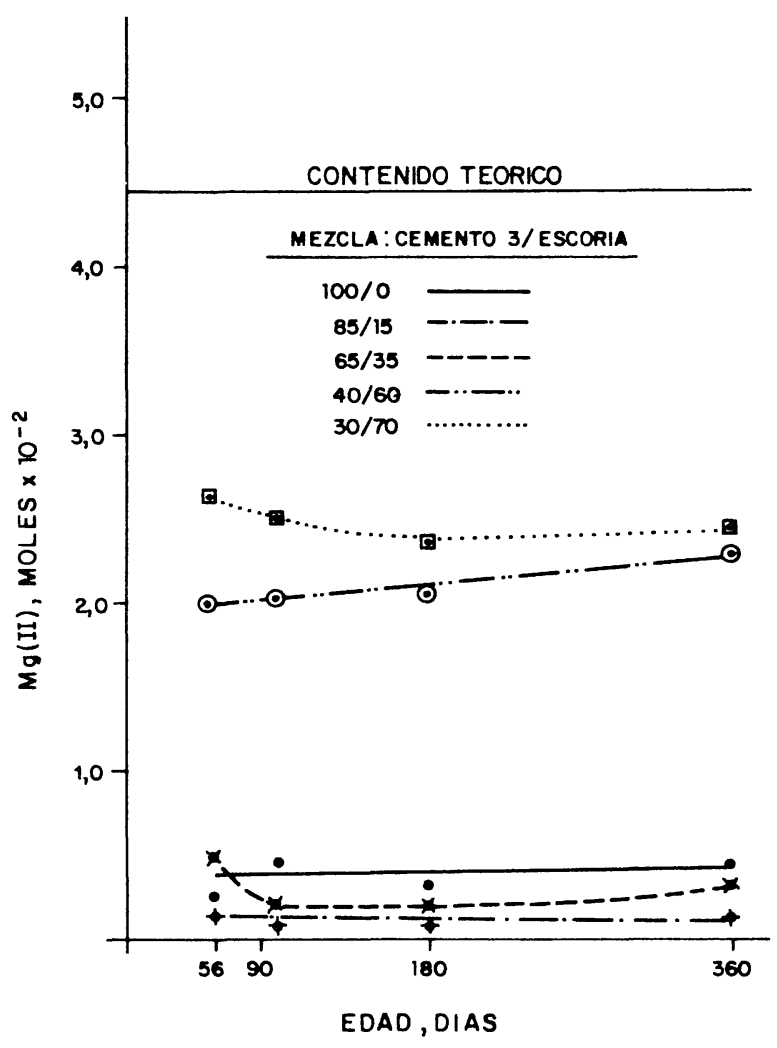

Fig. 6.-Sistema: cemento 3/escoria - agua de mar artificial ASTM. Evolución del contenido de Mg (II) en la disolución más en la fase sólida.

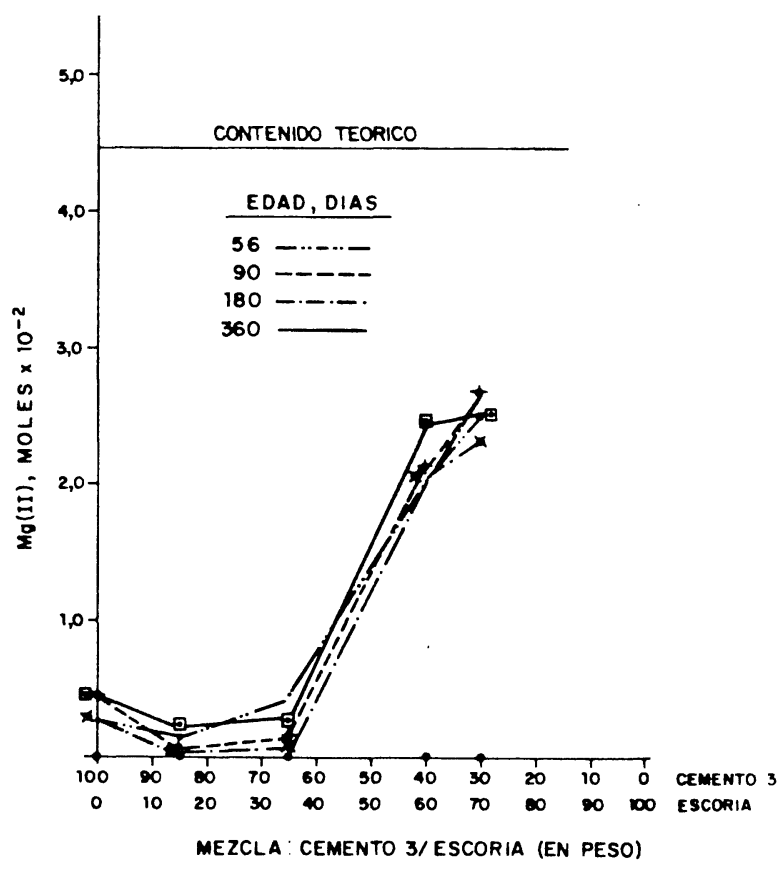

Fig. 7.-Sistema: cemento 3/escoria - agua de mar artificial ASTM. Evolución del contenido de $\mathrm{Mg}$ (II) en la disolución más en la fase sólida. 
segundo), en donde ha precipitado como $\mathrm{Mg}(\mathrm{OH})_{2}$, en forma de brucita (3). En los casos restantes (probetas elaboradas con las mezclas que tienen 35,60 y $70 \%$ de escoria) no se ha detectado o se ha encontrado en cantidades inferiores a $0,15 \times 10^{-2}$ moles.

En los DRX de las fracciones enriquecidas extraidas de las diversas series de probetas fabricadas con las mezclas cemento 3/escoria se han detectado por DRX los picos del compuesto cristalino brucita (3).

En la figura 6 se observa que la evolución del contenido de $\mathrm{Mg}$ (II) en las disoluciones en donde han estado sumergidas las series probetas de mortero, más el de las fases sólidas formadas, en función del tiempo de conservación-ataque sigue un hábito análogo en el caso de las series hechas con cemento 3 y con las mezclas cemento $3 /$ escoria $=85 / 15$ y $65 / 35$ (en peso).

Las cantidades de $\mathrm{Mg}$ (II) que existen en la disolución en donde han estado las distintas series de probetas, junto con las de la fase sólida, siguen una evolución análoga en las cuatro edades (figura 7), de tal modo que las cantidades de dicho $\mathrm{Mg}$ (II) en los medios de conservación-ataque de las series de probetas fabricadas con cemento 3 y con las mezclas cemento $3 /$ escoria $=85 / 15$ y $65 / 35$ (en peso) son menores de $0,6 \times 10^{-2}$ moles, para las cuatro edades estudiadas, mientras que para los otros dos casos (medios correspondientes a las probetas elaboradas con 60 y $70 \%$ de escoria) son mayores de $2,0 \times 10^{-2}$ moles para dichas edades, como se ha señalado anteriormente.

\subsection{Evolución del contenido de $\mathrm{SO}_{4}$ (II)}

En las figuras 8 y 9 se ha representado la evolución del contenido de iones sulfato, en la disolución y en la fase sólida, en función del tiempo de conservación-ataque para las series de probetas hechas con una mezcla, en la primera figura, y de la mezcla utilizada en la elaboración de las probetas de mortero, para cada edad, en la segunda figura.

El contenido de $\mathrm{SO}_{4}$ (II) en el agua de mar artificial ASTM D 1141-75 (2,44 × 10-2 moles/800 $\mathrm{ml}$ ) ha experimentado, en todos los casos estudiados, una disminución que depende del tiempo de conservación-ataque y de la mezcla cemento 3/escoria utilizada para fabricar las distintas series de probetas de mortero.

En la figura 8 se aprecia que el contenido de iones $\mathrm{SO}_{4}$ (II) en el agua de mar y en la fase sólida en donde han estado sumergidas las diversas series de probetas de mortero hechas con las mezclas cemento $3 /$ escoria $=65 / 35$, $40 / 60$ y $30 / 70$ (en peso) permanece prácticamente constante a lo largo del tiempo, habiendo experimentado la mayor disminución con relación al contenido del agua de mar - del orden de $0,7 \times 10^{-2}$ moles- en el primer caso; en los dos casos restantes dicha disminución se encuentra comprendida entre $0,1 \times 10^{-2}$ y

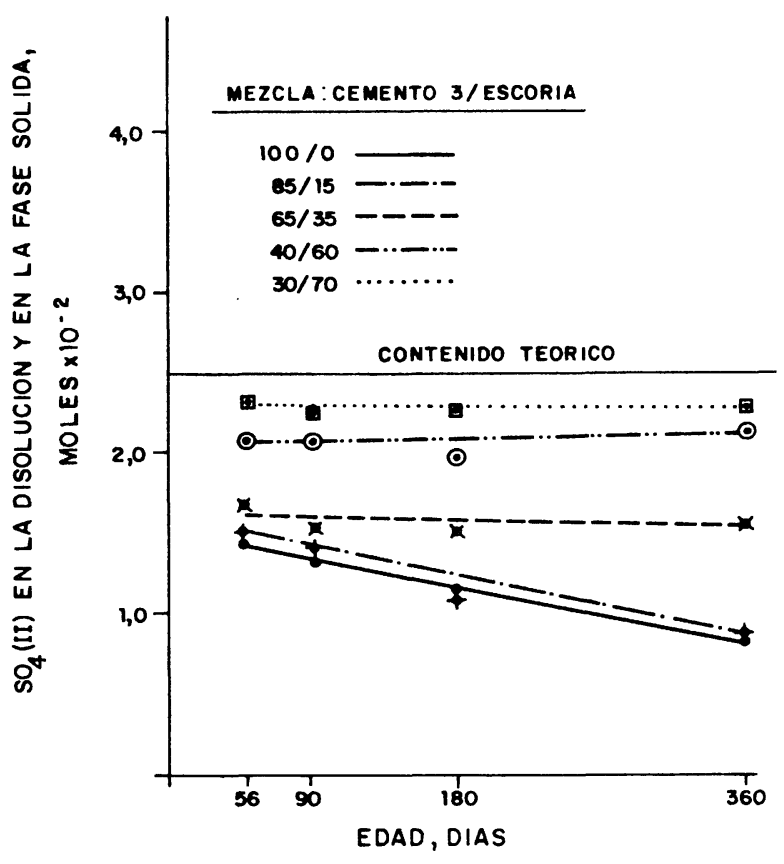

Fig. 8.-Sistema: cemento 3/escoria - agua de mar artificial ASTM. Evolución del contenido de $\mathrm{SO}_{4}$ (II) en la disolución y en la fase sólida.

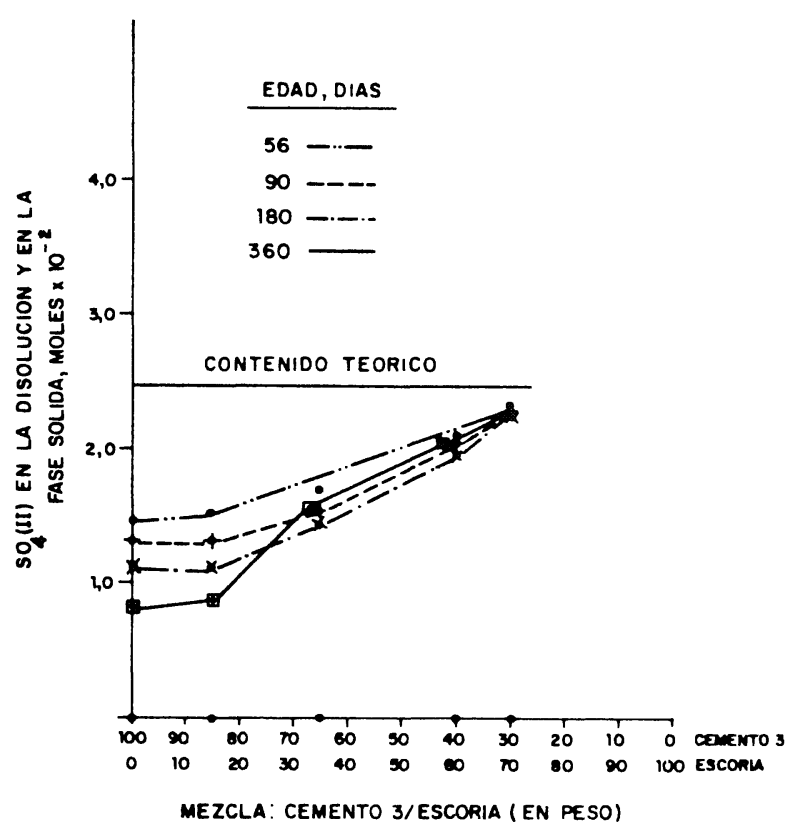

Fig. 9.-Sistema: cemento 3/escoria - agua de mar artificial ASTM. Evolución del contenido de $\mathrm{SO}_{4}$ (II) en la disolución y en la fase sólida. 
$0,4 \times 10^{-2}$ moles. Por el contrario, en los medios en donde han estado las probetas elaboradas con cemento 3 y con la mezcla que tiene el menor contenido de escoria (15\%) disminuye conforme aumenta el tiempo de conservación-ataque (figuras 8 y 9).

Las cantidades mayores desaparecidas de iones $\mathrm{SO}_{4}$ (II) del agua de mar artificial, fijadas por las probetas de mortero en donde se han formado los compuestos correspondientes, corresponden a las series hechas con cemento 3 , seguidas de las series elaboradas con las mezclas cemento $3 /$ escoria $=85 / 15$ y $65 / 35$ (en peso), respectivamente; hechos que están de acuerdo con la intensidad de los picos de la ettringita (3) y con las cantidades de iones $\mathrm{SO}_{4}$ (II) encontradas en la disolución y en la nueva fase sólida $\left(0,80 \times 10^{-2}\right.$ a $1,53 \times 10^{-2}$ moles, en los dos primeros casos, y $1,59 \times 10^{-2}$ a $1,70 \times 10^{-2}$ moles, en el tercer caso).

En las fracciones enriquecidas extraidas de una de las probetas de mortero de las distintas series hechas con cemento 3 y con las mezclas cemento $3 /$ escoria mencionadas se han detectado por DRX, entre otros, los picos del compuesto cristalino ettringita $\mathrm{y}$, en determinados casos, los del yeso secundario (3); la intensidad de dichos picos depende de la mezcla utilizada para fabricar las diversas series de probetas de mortero. La mayor intensidad de dichos picos corresponde a los diagramas de las muestras extraidas de las probetas hechas con cemento 3 , seguida de las elaboradas con la mezcla que tiene $15 \%$ de escoria, y la menor intensidad a los DRX de las mezclas que tienen los mayores contenidos de escoria (60 y $70 \%$ ); fenómenos que están de acuerdo con las determinaciones analíticas efectuadas.

\subsection{Evolución del contenido de $\mathrm{Cl}$ (I)}

El contenido de iones $\mathrm{Cl}$ (I) del agua de mar artificial ASTM D 1141-75 (44,2 $\times 10^{-2}$ moles en $800 \mathrm{ml}$, por serie de probetas) ha disminuído en todos los casos, excepto para los medios en donde han estado sumergidas durante 180 y 360 días las series de probetas hechas con cemento 3 y durante 360 días las restantes series elaboradas con las diversas mezclas cemento $3 /$ escoria (Tabla 1), que es del mismo orden.

Dicho contenido de iones $\mathrm{Cl}(\mathrm{I})$ es función de la mezcla cemento 3/escoria utilizada en la fabricación de las series de probetas de mortero y del tiempo de conservación-ataque (figuras 10 y 11). Las mayores cantidades se han encontrado en el agua de mar artificial en donde han estado las series de probetas de mortero hechas con cemento 3 , en donde en algunos casos es del mismo orden que el contenido del agua de mar, y con la mezcla que tiene $15 \%$ de escoria; las cantidades menores, que son del mismo orden, se han encontrado en los medios en donde han estado las series de probetas de mortero fabricadas con las mezclas cemento $3 /$ escoria $=65 / 35,40 / 60$ y $30 / 70$ (en peso).

En las fracciones enriquecidas, extraídas de una probeta de cada serie - hecha con las diversas mezclas cemento 3/escoria estudiadas - sumergida en agua de mar artificial $(800$ $\mathrm{ml}$ por serie y por edad) en los períodos de tiempo mencionados, se han identificado por DRX entre otros, los picos del compuesto cristalino sal de Friedel (3) con intensidad variable; la mayor intensidad corresponde a los diagramas de las muestras extraídas de las probetas elaboradas con las mezclas cemento 3/escoría $=65 / 35,40 / 60$ y $30 / 70$ (en peso), para

\section{MEZCLA: CEMENTO 3/ESCORIA}

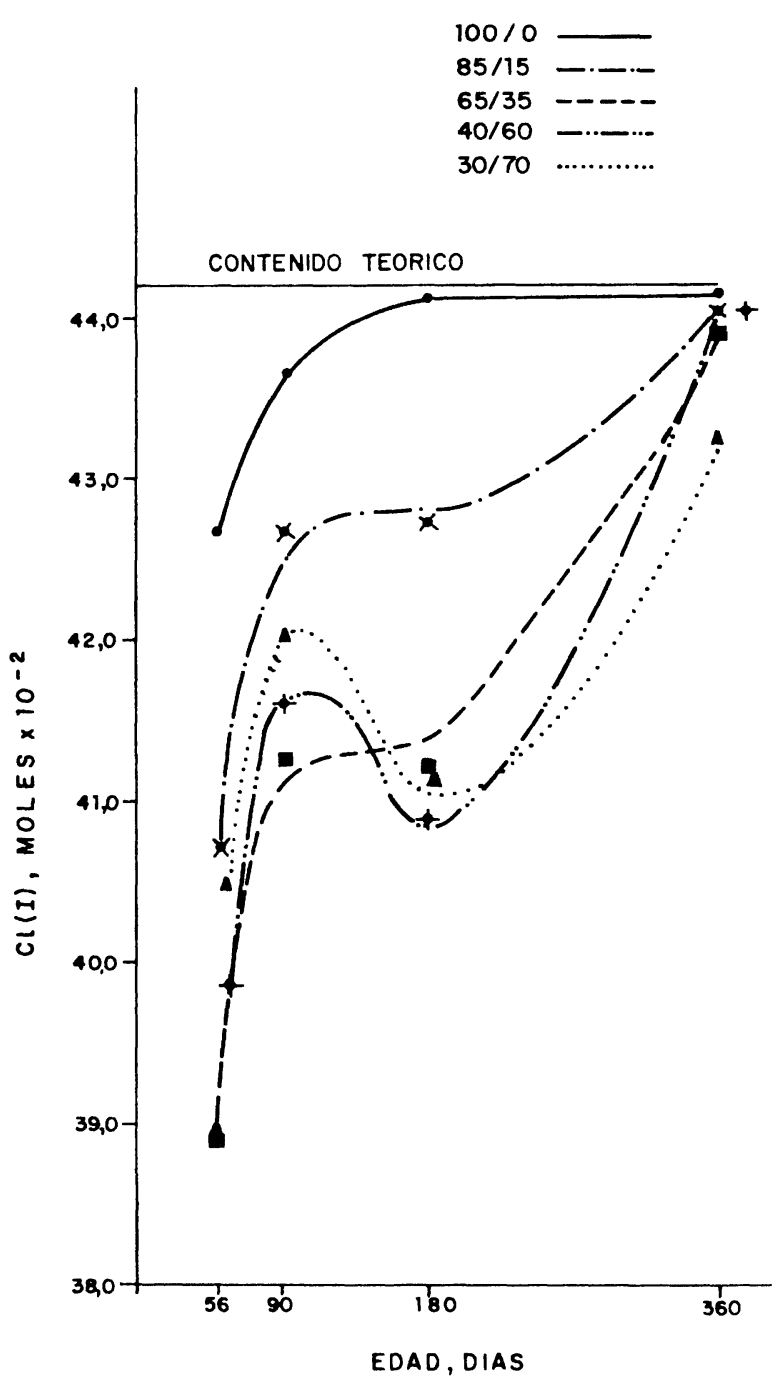

Fig. 10.-Sistema: cemento 3/escoria - agua de mar artificial ASTM. Evolución del contenido de $\mathrm{Cl}$ (I) en la disolución. 
todas las edades; fenómenos que están de acuerdo con las determinaciones analíticas realizadas.

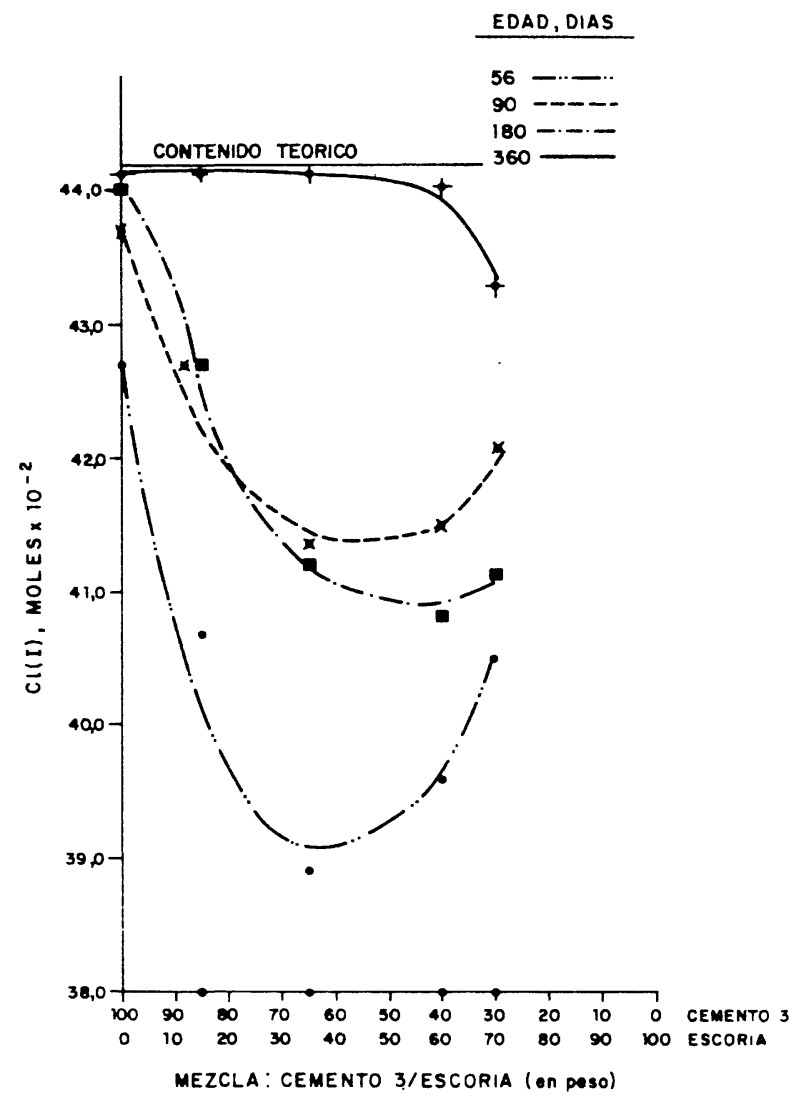

Fig. 11.-Sistema: cemento 3/escoria - agua de mar artificial ASTM. Evolución del contenido de Cl (I) en la disolución.

\section{INTERPRETACION DE RESULTADOS}

En el agua de mar artificial ASTM D 1141-75, en donde han estado sumergidas las diversas series de probetas de mortero $(800 \mathrm{ml}$ por serie y por edad) hechas con cemento 3 y con las mezclas cemento $3 /$ escoria $=85 / 15$, $65 / 35,40 / 60$ y $30 / 70$ (en peso) se han producido una serie de fenómenos como son: formación de una nueva fase sólida que ha precipitado en el medio, incremento de la cantidad de $\mathrm{Ca}$ (II) y del valor del $\mathrm{pH}$, y disminución del contenido de $\mathrm{Mg}$ (II), de $\mathrm{SO}_{4}$ (II) y de $\mathrm{Cl}$ (I).

El incremento de Ca (II), con relación al contenido de dicho ion en el agua de mar artificial $\left(1,04 \times 10^{-2}\right.$ moles $\left./ 800 \mathrm{ml}\right)$ es producido, fundamentalmente, por la disolución de parte del $\mathrm{Ca}(\mathrm{OH})_{2}\left(^{*}\right)$-formado como consecuencia de

(*) La solubilidad, a $20^{\circ} \mathrm{C}$, del $\mathrm{Ca}(\mathrm{OH})_{2}$ en agua es 1,230 $\mathrm{g} / \mathrm{l}(6)<>1,66 \times 10^{-2}$ moles/litro $<>1,33 \times 10^{-2}$ moles en $800 \mathrm{ml}$. las reacciones de hidratación de los compuestos del cemento $\left(\mathrm{C}_{3} \mathrm{~S}, \mathrm{C}_{2} \mathrm{~S}\right.$ y $\mathrm{CaO}$ libre $)$ - según:

$$
\begin{array}{cc}
\mathrm{H}_{2} \mathrm{O} & \mathrm{H}_{2} \mathrm{O} \\
\operatorname{mar} & \operatorname{mar} \\
\text { (A) } \mathrm{Ca}(\mathrm{OH})_{2} \cdot \text { sólido } & \mathrm{Ca}(\mathrm{OH})_{2} \cdot \text { disuelto } \rightleftharpoons \mathrm{Ca}(\mathrm{II})+ \\
& +2 \mathrm{OH}(\mathrm{I})
\end{array}
$$

dando lugar, además, a un incremento de iones $\mathrm{OH}(\mathrm{l}) \mathrm{y}$, por consiguiente, del valor del $\mathrm{pH}$, llegando a alcanzar valores superiores a 12.

La cantidad de $\mathrm{Ca}(\mathrm{OH})_{2}$ disuelto es función del que se forme en las reacciones de hidratación que, a su vez, depende de la mezcla cemento 3/escoria empleada en la fabricación de las diversas series de probetas; parte del $\mathrm{Ca}(\mathrm{OH})_{2}$ formado reacciona con la escoria para dar los compuestos de calcio correspondientes, como se señaló en (3).

Las cantidades totales de $\mathrm{Ca}$ (II) en las fases disueltas [Ca (II) del agua de mar artificial $\mathrm{ASTM}+\mathrm{Ca}$ (II) procedente de la disolución del $\mathrm{Ca}(\mathrm{OH})_{2}$ ] de cada uno de los sistemas parciales -es decir, de cada serie de probetas fabricadas con una misma mezcla cemento $3 /$ escoria, sumergidas durante $56-90-180$ y 360 días en agua de mar artificial ASTM (800 ml)-, junto con el correspondiente a las nuevas fases sólidas (Tabla 1), se encuentra en el entorno representado en la figura 12, presentando los valores medios, para todas las edades, que se reseñan en la tabla 2 , en donde figuran, junto a los valores medios anteriores, las cantidades de $\mathrm{Ca}$ (II) teóricas, calculadas a partir del valor medio que corresponde al sistema parcial cemento 3 (100\%)-agua de mar artificial ASTM (para las cuatro edades). En la figura 12 , en donde se han representado dichos valores medios, se puede apreciar que la cantidad de $\mathrm{Ca}$ (II) es, prácticamente, función lineal de la cantidad de cemento 3 presente en las mencionadas mezclas, en las cuales se produce un aporte de $\mathrm{Ca}$ (II) $\left\langle>\mathrm{Ca}(\mathrm{OH})_{2}\right.$ disuelto, que se ha designado como aditivo, de tal modo que en la disolución más en la nueva fase sólida se encuentran las cantidades experimentales obtenidas en el caso de las probetas hechas con cemento 3 sin adición de escoria $\left(5,86 \times 10^{-2}\right.$ moles en $800 \mathrm{ml}$; valor medio) y cero moles cuando no existe cemento; este fenómeno se ha puesto de manifiesto en el caso de otros dos cementos, de características estructurales distintas entre sí y a las del cemento 3 , y de sus mezclas con las mismas cantidades de escoría, objeto de las publicaciones (7) (8).

El equilibrio (A) se ve afectado, en este caso, por la presencia de los iones presentes en el agua de mar artificial no comunes, distintos 


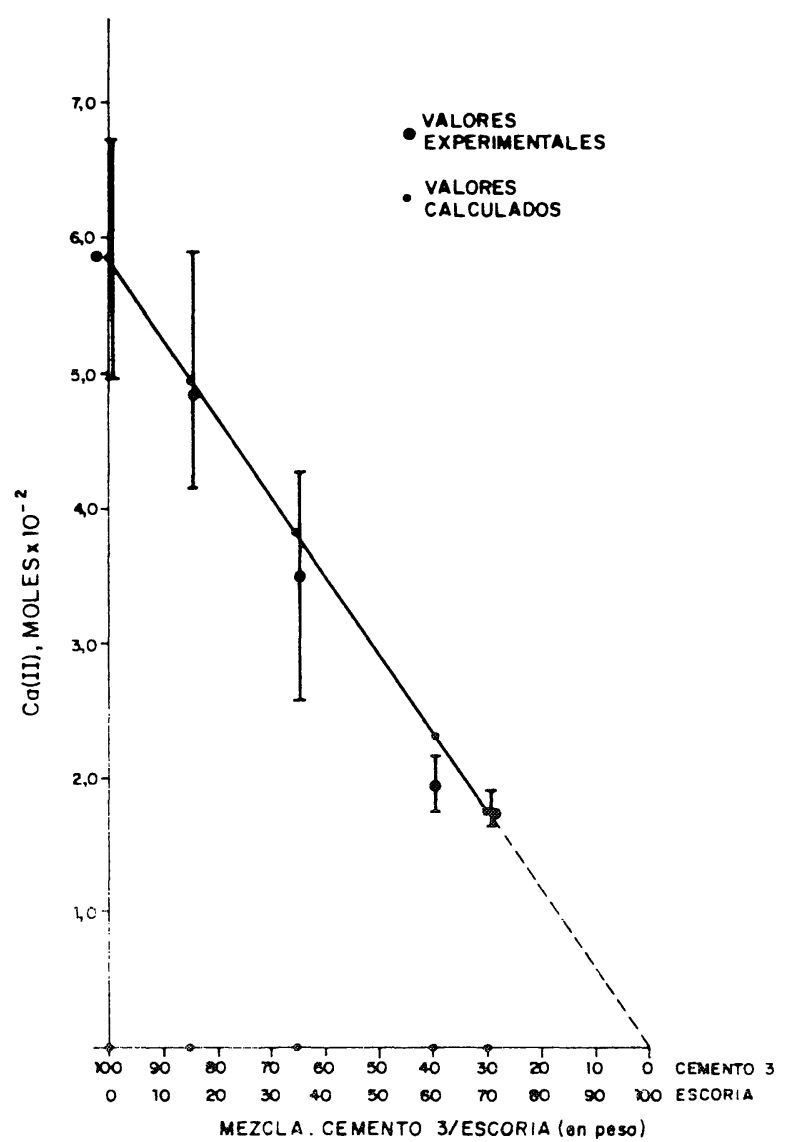

Fig. 12.-Sistema: cemento 3/escoria - agua de mar artificial ASTM. Evolución del contenido de Ca (II) total.

\section{TABLA 2}

Sistema: cemento 3/escoria-agua de mar artificial ASTM.

Cantidades de Ca (II) en la fase líquida y en la fase sólida: valores medios experimentales y calculados

\begin{tabular}{|c|c|c|}
\hline \multirow{2}{*}{ Mezcla: } & \multicolumn{2}{|c|}{ Ca (II); moles $\times 10^{-2}$} \\
\cline { 2 - 3 } & $\begin{array}{c}\overline{\mathbf{X}} \\
\text { escoria }\end{array}$ & $\begin{array}{c}\overline{\bar{x}} \\
\text { calculado }\end{array}$ \\
\cline { 2 - 3 } $100 / 0$ & 5,86 & 5,86 \\
$85 / 15$ & 4,81 & 4,98 \\
$65 / 35$ & 3,48 & 3,81 \\
$40 / 60$ & 1,96 & 2,34 \\
$30 / 70$ & 1,76 & 1,76 \\
\hline
\end{tabular}

del Ca (II), que no producen otras reacciones - efecto salino- $y$, además, por la existencia de otros iones o compuestos que dan lugar a reacciones de precipitación con los iones $\mathrm{Ca}$ (II) o con los iones $\mathrm{OH}$ (I) del mencionado equilibrio $(A)$, como son las siguientes:
(B) $\mathrm{Ca}$ (II) $+2 \mathrm{OH}$ (I) $+\mathrm{CO}_{2} \stackrel{\mathrm{H}_{2} \mathrm{O}}{\rightleftharpoons} \mathrm{CaCO}_{3}$.sólido + $+\mathrm{H}_{2} \mathrm{O}$

(C) $\mathrm{Ca}$ (II) $+\mathrm{SO}_{4} \stackrel{\stackrel{\mathrm{H}_{2} \mathrm{O}}{\rightleftharpoons}}{\rightleftharpoons} \mathrm{CaSO}_{4} \cdot 2 \mathrm{H}_{2}$ O.sólido

(D) $\quad \mathrm{Mg}$ (II) $+2 \mathrm{OH}(\mathrm{I}) \stackrel{\mathrm{O}}{\rightleftharpoons} \mathrm{Mg}(\mathrm{OH})_{2}$. sólido

las cuales producen, en un determinado grado, la disminución de iones $\mathrm{Ca}$ (II) -equilibrios (B) y (C)- y $\mathrm{OH}(\mathrm{I})$-equilibrios (B) y (D)- favoreciendo, así mismo, la disolución del $\mathrm{Ca}(\mathrm{OH})_{2}$ y el avance de las reacciones de hidratación.

El pH del agua de mar artificial ASTM $(6,5)$ alcanza valores superiores a 11,5 en los medios en donde han estado las series de probetas de mortero hechas con cemento 3 y con la mezcla que tiene el $15 \%$ de escoria (en peso) y superiores a 7,5 e inferiores a 10 en los casos restantes, que corresponden a las series de probetas fabricadas con las mezclas que tienen los mayores contenidos de escoria $(35,60$ y $70 \%)$, como consecuencia de la menor cantidad de $\mathrm{Ca}(\mathrm{OH})_{2}$ puesta en juego.

$\mathrm{El} \mathrm{CO}_{2}$ disuelto en el agua de mar ASTM reacciona, en medio básico fuerte, con el $\mathrm{Ca}$ (II) que se encuentra en la fase disuelta, para dar carbonato de calcio, según $(E)$ :

$$
\begin{gathered}
\mathrm{CO}_{2}+\mathrm{Ca}(\mathrm{II})+2 \mathrm{OH}(\mathrm{I}) \rightleftharpoons \\
\rightleftharpoons \mathrm{CaCO}_{3} \text {.sólido }+\mathrm{H}_{2} \mathrm{O}
\end{gathered}
$$

compuesto que ha precipitado como calcita $y$ como aragonito, como se probó en (3) por DRX, dando lugar a una nueva fase sólida, produciéndose también una disminución de la concentración de iones $\mathrm{OH}$ (I) y, por lo tanto, del valor del $\mathrm{pH}$. Para que esta reacción tenga lugar se ha de cumplir:

$$
\left[\mathrm{CO}_{3}(\mathrm{II})\right][\mathrm{Ca}(\mathrm{II})]>\mathrm{P}_{\mathrm{s}}\left(4,8 \times 10^{-9}\right)
$$

teniendo en cuenta que:

$$
\mathrm{CO}_{2}+2 \mathrm{OH}(\mathrm{I}) \rightleftharpoons \mathrm{CO}_{3}(\mathrm{II})+\mathrm{H}_{2} \mathrm{O}
$$

El Mg (II) presente en el agua de mar artificial ASTM, a $\mathrm{pH}$ básico fuerte $(\mathrm{pH}>10)$, reacciona con los iones $\mathrm{OH}$ (l) precipitando como brucita según:

(F) $\quad \mathrm{Mg}(\mathrm{II})+2 \mathrm{OH}(\mathrm{I})=\mathrm{Mg}(\mathrm{OH})_{2}$. sólido

por cumplirse:

$$
[\mathrm{Mg}(\mathrm{II})][\mathrm{OH}(\mathrm{I})]^{2}>\mathrm{P}_{\mathrm{s}}\left(1,8 \times 10^{-11}\right)
$$


Esta reacción lleva consigo una disminución del $\mathrm{pH}$. La precipitación del $\mathrm{Mg}(\mathrm{OH})_{2}$ ha tenido lugar en los medios en donde han estado sumergidas las diversas series de probetas (a todas las edades) hechas con cemento $3 y$ con la mezcla que tiene el $15 \%$ de escoria, en donde existía un $\mathrm{pH}>11,5$, habiéndose detectado por DRX (3) en la fase sólida el compuesto cristalino brucita, en donde el $\mathrm{Mg}$ (II) se encuentra en cantidades inferiores a $0,5 \times$ $\times 10^{-2}$ moles, habiendo desaparecido de la fase líquida; el resto ( $4 \times 10^{-2}$ moles) ha precipitado en el seno de las probetas de mortero como brucita (3), según:

$$
\begin{aligned}
& \mathrm{Mg}(\mathrm{II})+\frac{\mathrm{Ca}(\mathrm{OH})_{2} \cdot \text { disuelto }}{(\text { Probeta })} \\
& =\frac{\mathrm{Mg}(\mathrm{OH})_{2} \text {.sólido }+\mathrm{Ca}(\mathrm{II})}{\text { (probeta) }}
\end{aligned}
$$

de tal modo que por cada mol de iones $\mathrm{Mg}$ (II) que ha precipitado, queda libre otro de $\mathrm{Ca}$ (II), el cual reacciona con los compuestos de la escoria o se encuentra en la disolución y en la nueva fase sólida.

Por el contrario, en el agua de mar artificial en donde han estado sumergidas las probetas de mortero fabricadas con las mezclas cemento $3 /$ escoria $=40 / 60$ y $30 / 70$ (en peso) no ha precipitado el ion $\mathrm{Mg}$ (II), por no darse las condiciones adecuadas; dicho ion se ha encontrado en la disolución en cantidades superiores a $2,0 \times 10^{-2}$ moles e inferiores a $2,7 \times 10^{-2}$ moles, el resto se encuentra en las probetas de mortero en donde ha precipitado como brucita (3), de acuerdo con la reacción (G).

En el agua de mar artificial ASTM, en donde han estado las series de probetas hechas con la mezcla cemento $3 /$ escoria $=65 / 35$ (en peso), se ha encontrado $\mathrm{Mg}$ (II) tanto en la nueva fase sólida (en determinadas edades y en cantidades inferiores a $0,1 \times 10^{-2}$ moles) como en la disolución (en cantidades comprendidas entre $0,1 \times 10^{-2}$ y $0,5 \times 10^{-2}$ moles) por no darse las condiciones adecuadas para que tenga lugar la reacción de precipitación; el resto ha precipitado en el seno de las probetas de mortero como brucita (3), según la reacción (G).

En la figura 13 se ha representado la evolución de los contenidos de $\mathrm{Mg}$ (II) y de $\mathrm{Ca}$ (II) en la disolución [Ca (II) que procede del $\mathrm{Ca}(\mathrm{OH})_{2}$ disuelto + $\mathrm{Ca}$ (II) del agua de mar artificial ASTM] más en la nueva fase sólida, gráficas 1 y 3 respectivamente, además de la del $\mathrm{Ca}$ (II) en la disolución más en la nueva fase sólida, que procede del $\mathrm{Ca}(\mathrm{OH})_{2}$ disuelto, gráfica 2 , en función de la mezcla cemento 3/escoria utilizada para fabricar las diversas series de probetas de mortero, para cada período de
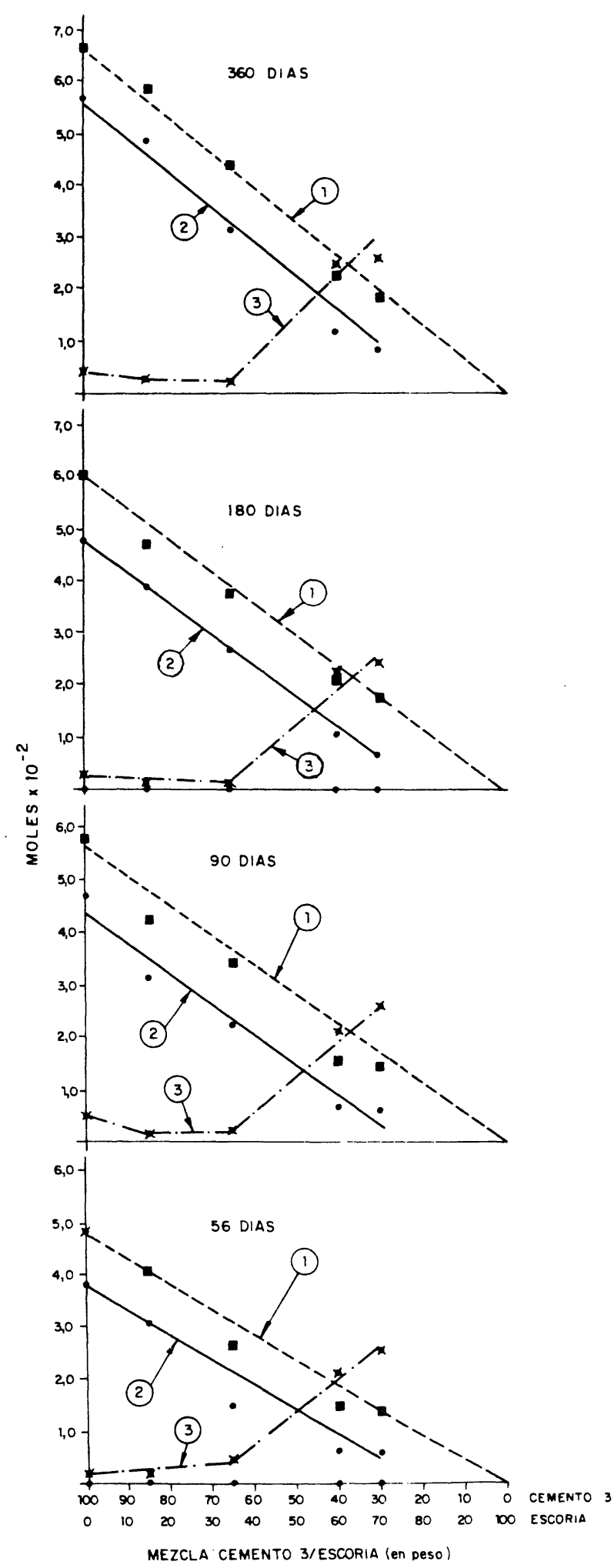

Fig. 13.-Sistema: cemento 3/escoria - agua de mar artificial ASTM. Evolución de los contenidos de Ca (II) y de $\mathrm{Mg}$ (II)

Gráfica 1.-Ca (II) en la disolución + Ca (II) en la fase sólida. Ca (II) en la disolución = $\mathrm{Ca}$ (II) que procede del $\mathrm{Ca}(\mathrm{OH})_{2}$ disuelto $+\mathrm{Ca}$ (II) del agua de mar.

Gráfica 2.-Ca (II) en la disolución que procede del $\mathrm{Ca}(\mathrm{OH})_{2}$ disuelto $+\mathrm{Ca}$ (II) en la fase sólida $=\mathrm{Ca}$ (II) total disuelto.

Gráfica 3.- Mg (II) en la disolución + Mg (II) en la fase sólida. 
conservación-ataque. En dicha figura se puede observar que ambos contenidos [de $\mathrm{Ca}$ (II) y de $\mathrm{Mg}$ (II)] están íntimamente relacionados, existiendo un punto de cruce en las gráficas 2 y 3 , que corresponde a la mezcla cemento $3 /$ escoria $=50 / 60$ (en peso), en donde tiene lugar el equilibrio de intercambio iónico:

$\begin{array}{ccc}\text { Ca (II) } & \text { Mg (II) } \\ \begin{array}{c}\text { (que pase a la } \\ \text { disolución) }\end{array} & & \begin{array}{l}\text { (que desaparece } \\ \text { de la disolución) }\end{array}\end{array}$

que responde al equilibrio $(G)$, al reaccionar los iones $\mathrm{Mg}$ (II) con los iones $\mathrm{OH}$ (I) en la interfase del equilibrio $\mathrm{Ca}(\mathrm{OH})_{2}$. sólido $\rightleftharpoons$ $\rightleftharpoons \mathrm{Ca}(\mathrm{OH})$.disuelto, según:

$$
\begin{aligned}
& \mathrm{Ca}(\mathrm{OH})_{2} \text {. sólido } \rightleftharpoons \mathrm{Ca}(\mathrm{OH})_{2} \text {.disuelto } \rightleftharpoons \\
& \rightleftharpoons \frac{\mathrm{Ca}(\mathrm{II})+2 \mathrm{OH}(\mathrm{I})}{\mathrm{Mg}(\mathrm{II})} \\
& 11 \\
& \mathrm{Mg}(\mathrm{OH})_{2} \text {.sólido }+\mathrm{Ca} \text { (II) }
\end{aligned}
$$

en donde, se puede apreciar, que por cada mol de iones $\mathrm{Ca}$ (II) puesto en juego desaparece otro de $\mathrm{Mg}$ (II). En los casos de las probetas hechas con mezclas que tienen cantidades de escoria inferiores al $60 \%$, las cantidades de $\mathrm{Ca}$ (II) en el agua de mar -en donde han estado sumergidas - son superiores a las de $\mathrm{Mg}$ (II), ya que durante la hidratación del cemento se genera más $\mathrm{Ca}(\mathrm{OH})_{2}$, quedando parcialmente libre mayor cantidad que facilita la precipitación del $\mathrm{Mg}$ (II), por una parte, y la disolución del $\mathrm{Ca}(\mathrm{OH})_{2}$, por otra. Por el contrario, en los casos de las probetas fabricadas con mezclas que tienen cantidades de escoria iguales o superiores al $60 \%$ se invierte el fenómeno, quedando en la disolución, fundamentalmente, y en la nueva fase sólida contenidos mayores de $\mathrm{Mg}$ (II) que de $\mathrm{Ca}$ (II) por no darse las condiciones para que precipite el ion $\mathrm{Mg}$ (II), al no existir cantidad suficiente de iones $\mathrm{OH}(\mathrm{l})$, ya que no se ha generado la cantidad suficiente de $\mathrm{Ca}(\mathrm{OH})_{2}$. Los hechos mencionados, puestos de manifiesto en (7) (8), influyen en el grado de resistencia química de los cementos.

La disminución que experimenta el contenido de iones $\mathrm{SO}_{4}$ (II) en el agua de mar artificial ASTM, en donde han estado sumergidas las diversas series de probetas de mortero, está intimamente ligada a las características del cemento y de la escoria, así como a la mezcla utilizada para fabricar dichas series de probetas de mortero y al tiempo de conservaciónataque, que influyen en la formación de compuestos a base de sulfatos (yeso secundario y, de un modo especial, ettringita) en las probetas de mortero, como se probó por DRX (3), al reaccionar con los iones $\mathrm{Ca}$ (II), procedentes del $\mathrm{Ca}(\mathrm{OH})_{2}$, y con el aluminato de calcio hidratado del cemento, equilibrios $(H)(I)$, por una parte

(H) $\mathrm{Ca}$ (II) $+\mathrm{SO}_{4}$ (II) $+2 \mathrm{H}_{2} \mathrm{O} \rightleftharpoons \mathrm{CaSO}_{4} \cdot 2 \mathrm{H}_{2} \mathrm{O}$

(l)

$$
\begin{gathered}
\frac{3 \mathrm{Ca}(\mathrm{II})+3 \mathrm{SO}_{4}(\mathrm{II})+}{3\left(\mathrm{CaSO}_{4} \cdot 2 \mathrm{H}_{2} \mathrm{O}\right)}+ \\
+3 \mathrm{CaO} \cdot \mathrm{Al}_{2} \mathrm{O}_{3} \cdot 6 \mathrm{H}_{2} \mathrm{O}+25 \mathrm{H}_{2} \mathrm{O} \rightleftharpoons \\
\rightleftharpoons 3 \mathrm{CaO} \cdot \mathrm{Al}_{2} \mathrm{O}_{3} \cdot 3 \mathrm{CaSO}_{4} \cdot 31 \mathrm{H}_{2} \mathrm{O}
\end{gathered}
$$

$y$, por otra, con los aluminatos de la escoria, procedentes del posible desdoblamiento de la gehelenita presente en la misma al reaccionar con el $\mathrm{Ca}(\mathrm{OH})_{2}$ del cemento hidratado, equilibrio $(\mathrm{J})$, que se ha representado en función del contenido de clínker, según:

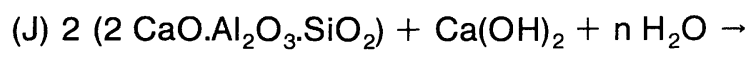
escoria vítrea

$$
\begin{aligned}
\underset{\text { bastante clinker }}{\text { poco clinker }} \rightarrow & 2\left(2 \mathrm{CaO} \cdot \mathrm{Al}_{2} \mathrm{O}_{3} .7 \mathrm{H}_{2} \mathrm{O}\right) \stackrel{\mathrm{CaO} \cdot \mathrm{Al}_{2} \mathrm{O}_{3} .13 \mathrm{H} \mathrm{H}_{2} \mathrm{O} \underset{\mathrm{Ca}(\mathrm{OH})_{2}}{\stackrel{\mathrm{CH})_{2}}{\longrightarrow}}}{\rightarrow} 3 \mathrm{CaO} \cdot \mathrm{Al}_{2} \mathrm{O}_{3} \cdot \eta \mathrm{H}_{2} \mathrm{O}
\end{aligned}
$$

lo que hace que, para un clínker y una escoria dados, la cantidad de ambos en la mezcla influya en la de iones $\mathrm{SO}_{4}$ (II) fijados para formar ettringita; a veces, se presentan valores de la misma magnitud que en el caso de utilizar cemento 3 sin adición de escoria, como sucede en los sistemas parciales que corresponden a las series de probetas hechas con las mezclas que tienen $15 \%$, fundamentalmente, y $35 \%$ de escoria.

La disminución de iones $\mathrm{Cl}$ (I) del agua de mar artificial ASTM, en donde han estado sumergidas las probetas de mortero hechas con las diversas mezclas del cemento 3 con la escoria utilizadas en este trabajo, se debe a la formacion de la sal de Friedel en las mencionadas probetas de mortero (3), por reacción de dichos iones con los iones $\mathrm{Ca}$ (II), que proceden del $\mathrm{Ca}(\mathrm{OH})_{2}$, y con los aluminatos de calcio hidratados del cemento, como con los generados en el posible desdoblamiento de la gehelenita de la escoria, mencionado anteriormente; la reaccón que tiene lugar es:

$$
\begin{gathered}
3 \mathrm{CaO} \cdot \mathrm{Al}_{2} \mathrm{O}_{3} \cdot 6 \mathrm{H}_{2} \mathrm{O}+\frac{\mathrm{Ca}(\mathrm{II})+2 \mathrm{Cl}(\mathrm{I})}{\mathrm{CaCl}_{2}}+4 \mathrm{H}_{2} \mathrm{O}= \\
=3 \mathrm{CaO} \cdot \mathrm{Al}_{2} \mathrm{O}_{3} \cdot \mathrm{CaCl}_{2} \cdot 10 \mathrm{H}_{2} \mathrm{O}
\end{gathered}
$$




\section{CONCLUSIONES}

\section{Primera:}

En el agua de mar artificial ASTM (D 1141-75) en donde han estado sumergidas las diversas series de probetas de mortero $(1: 3)$, hechas con un cemento portland (cemento 3 ) y con las mezclas cemento/escoria estudiadas en este trabajo $(85 / 15-65 / 35-40 / 60$ y $30 / 70$, en peso), se produce un aumento de la concentración de iones $\mathrm{Ca}$ (II) y del valor del $\mathrm{pH}$, una disminución de la concentración de iones $\mathrm{Mg}$ (II), $\mathrm{SO}_{4}$ (II) y $\mathrm{Cl}$ (I), así como la formación de una nueva fase sólida, que son función de la mezcla utilizada para fabricar las mencionadas series de probetas y del tiempo de conservación-ataque.

\section{Segunda:}

La cantidad de fase sólida formada en el agua de mar en donde han estado sumergidas las diversas series de probetas de mortero ( 800 $\mathrm{ml}$ ), hechas con una misma mezcla, aumenta con el tiempo de conservación-ataque y disminuye, para una misma edad, según lo hace la cantidad de cemento en la mezcla utilizada para fabricar las mencionadas series de probetas.

\section{Tercera:}

El contenido de $\mathrm{Ca}$ (II) en la fase líquida más en la nueva fase sólida, que procede de un modo especial del $\mathrm{Ca}(\mathrm{OH})_{2}$ disuelto del cemento hidratado, para cada mezcla (cemento 3/escoria) utilizada en la fabricación de las distintas series de probetas de mortero, aumenta con el tiempo de conservación-ataque $y$, para cada edad, disminuye bruscamente conforme lo hace el contenido de cemento 3 de la mencionada mezcla.

Los valores medios de los contenidos totales de $\mathrm{Ca}$ (II) -que se encuentra en la disolución más en la nueva fase sólida, es decir Ca (II) del agua de mar más $\mathrm{Ca}$ (II) procedente del $\mathrm{Ca}(\mathrm{OH})_{2}$ disuelto- de cada conjunto de probetas hechas con cemento 3 y con las diversas mezclas cemento $3 /$ escoria para cada edad corresponde, prácticamente, a las cantidades teóricas, calculadas a partir del valor medio del contenido total de $\mathrm{Ca}$ (II) del agua de mar artificial, en donde han estado sumergidas las series de probetas elaboradas solo con cemento 3 .

\section{Cuarta:}

El contenido de $\mathrm{Mg}$ (II) del agua de mar artificial ASTM, en donde han estado sumergidas las distintas series de probetas de mortero, experimenta una disminución que es función de la mezcla utilizada para fabricar las diversas series de dichas probetas y del tiempo de conservación-ataque.

En el agua de mar, en donde han estado las series de probetas de mortero hechas con cemento 3 y con la mezcla que tiene el menor contenido de escoria (15\%), el ion Mg (II) ha desaparecido; ha precipitado como brucita en la nueva fase sólida y en la probeta. En los otros casos, dicho ion $\mathrm{Mg}$ (II), se encuentra en la fase líquida en cantidades diversas, y en la nueva fase sólida en cantidades del orden de miligramos; el resto ha precipitado como brucita en la probeta.

\section{Quinta:}

La evolución del contenido de Ca (II) está íntimamente ligada con la de Mg (II), de tal modo que cuando el de uno aumenta, el del otro disminuye y viceversa. En este sistema existe un punto de corte que corresponde al equilibrio iónico $\mathrm{Ca}$ (II) $\rightleftharpoons \mathrm{Mg}$ (II).

\section{Sexta:}

$\mathrm{El}$ contenido de los iones $\mathrm{SO}_{4}$ (II) y $\mathrm{Cl}$ (I) del agua de mar, en donde han estado sumergidas las distintas series de probetas de mortero, experimenta una disminución que es función de la mezcla utilizada para fabricar dichas series de probetas de mortero y del tiempo de conservación-ataque. Dicha disminución es más pronunciada en los medios en donde han estado las probetas hechas con cemento 3 y con las mezclas que tienen 15 y $35 \%$ de escoria (en peso), para los iones $\mathrm{SO}_{4}$ (II), y en los medios en donde han estado las probetas elaboradas con las mezclas que tienen los tres mayores contenidos de escoria $(35,60$ y $70 \%$, en peso), para los iones $\mathrm{Cl}(\mathrm{l})$.

\section{BIBLIOGRAFIA}

(1) SAGRERA-MORENO, J. L. y GASPAR-TEBAR, D. (1980): Resistencia química del hormigón: VIII. Accion del agua de mar: influencia de la adición de escoria a un cemento portland. Evolución de las resistencias mecánicas a flexotracción y del coeficiente de corrosión. Materiales de Construcción, octubre-noviembre-diciembre, 180, 99-120.

(2) GASPAR-TEBAR, D. y SAGRERA-MORENO, J. L. (1981): Resistencia química del hormigón: XII. Influencia de la adición de escoria a un cemento portland. Estudio por DRX del sistema cemento 3/escoria-agua potable filtrada. Materiales de Construcción, julio-agosto-septiembre, 183, 33-44. 
(3) GASPAR-TEBAR, D. y SAGRERA-MORENO, J. L. (1983): Resistencia química del hormigón: XX. Acción del agua de mar: influencia de la adición de escoria a un cemento portland. Estudio por DRX. Materiales de Construcción, abrilmayo-junio-julio-agosto-septiembre, 190-191, 3-24.

(4) GASPAR-TEBAR, D. y SAGRERA-MORENO, J. L. (1986): Resistencia química del hormigón: XXV. Influencia de la adición de escoria a un cemento portland. Estudio de la concentración iónica del sistema cemento 3/escoria-agua potable filtrada. Materiales de Construcción, abril-mayo-junio, 202, 49-55.

(5) GASPAR-TEBAR, D. y SAGRERA-MORENO, J. L. (1982): Resistencia química del hormigón: XVI. Acción del agua de mar: influencia de la adición de escoria a un cemento portland de alta resistencia inicial. Estudio por DRX. Materiales de Construcción, abril-mayo-junio,186, 40.

(6) BICZOK, I. (1972): Corrosión y Protección del Hormigón. Ed. Urmo. Bilbao, pág. 211.

(7) GASPAR-TEBAR, D. y SAGRERA-MORENO, J. L. (1984): Resistencia química del hormigón: XXII. Influencia de la adición de escoria a un cemento portland de alta resistencia inicial. Estudio de la concentración iónica del sistema cemento 1/escoria-agua de mar artificial. Materiales de Construcción, abril-mayo-junio, 193, 51-68.

(8) GASPAR-TEBAR, D. y SAGRERA-MORENO, J. L. (1984): Resistencia química del hormigón: XXIV. Influencia de la adición de escoria a un cemento portland resistente al yeso. Estudio de la concentración iónica del sistema cemento 2/escoria-agua de mar artificial. Materiales de Construcción, octubre-noviembre-diciembre, 196, 49-66.

\section{RECONOCIMIENTO}

Nuestro más sincero agradecimiento a las personas del Equipo de Durabilidad del IETcc: Amalia Rodríguez Pereíra, Lucila López Solana, M. ${ }^{a}$ Soledad Cid Fernández y Felipe Cantero Palacios, así como a M. ${ }^{a}$ Isabel Jiménez, por su valiosa colaboración en la realización de este trabajo.

\section{publicaciones del i.e.t.c.c.}

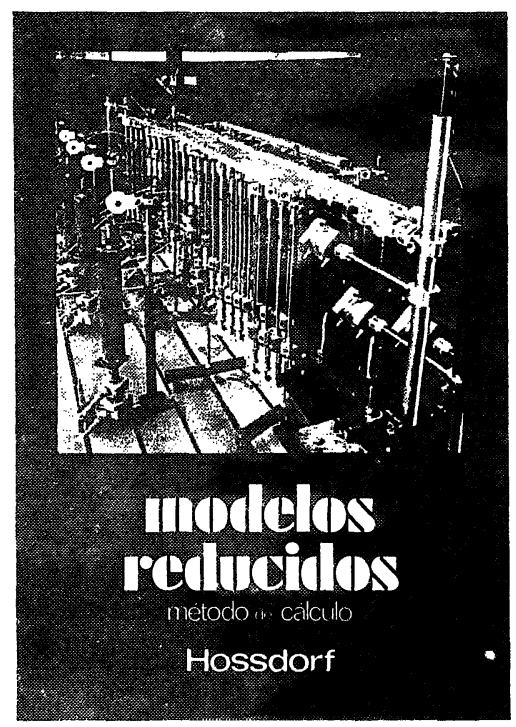

Modelos reducidos. Mátodo de cálculo

H. Hossdorf, Ingeniero Civil

La técnica de los ensayos en modelos reducidos de estructuras sufre hoy dia una decisiva metamorfosis. Hasta hace poco era un medio más bien de artesania, que no siempre era tomado en serio por los académicos teorizantes para comprender el comportamiento resistente de las estructuras complejas $y$ a que se acudió las más de las veces, como a un ültimo remedio debido a sus indiscutibles insuficiencias. Sin embargo, en poco tiempo y gracias a su conexión con los ordenadores digitales, se ha transformado en un instrumento cientificamente valioso, que no puede quedar a un lado en la práctiça diaria del Ingeniero Proyectista.

Un volumen encuadernado en cartoné plastificado con lomo de tela, de $17 \times 24 \mathrm{~cm}$, compuesto de 250 páginas, 158 figuras $y$ fotografias.

Precios: 1.800 ptas.; \$ USA 26.00

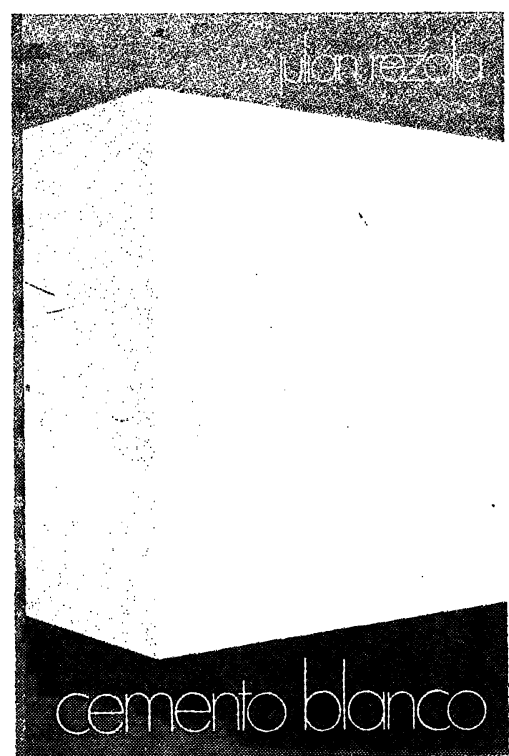

\section{Cemento blanco}

Julián Rezola

Ingeniero Ouimico Dipl \& O S.

Sabido es que existe una extensa y documentada bibliografía sobre el cemento gris: en cambio, no puede decirse lo mismo acerca del cemento portland blanco, ya que los escritos existentes se refieren tan sólo a algunas peculiaridades que le distinguen de aquét.

El autor nos ofrece sus profundos conocimientos yu larga experiencia tanto en laboratorio como en fabricación.

La parte descriptiva del libro se complementa con gráficos, diagramas y fotografias de gran utilidad

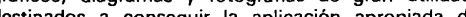
lomerante.

Un volumen encuadernado en cartoné policerado, de $17,4 \times 24,3 \mathrm{~cm}$, compuesto de 395 páginas. numerosas figuras, tablas $y$ abacos.

Precios: España, 1.700 ptas.; extranjero. $\$ 24.00$

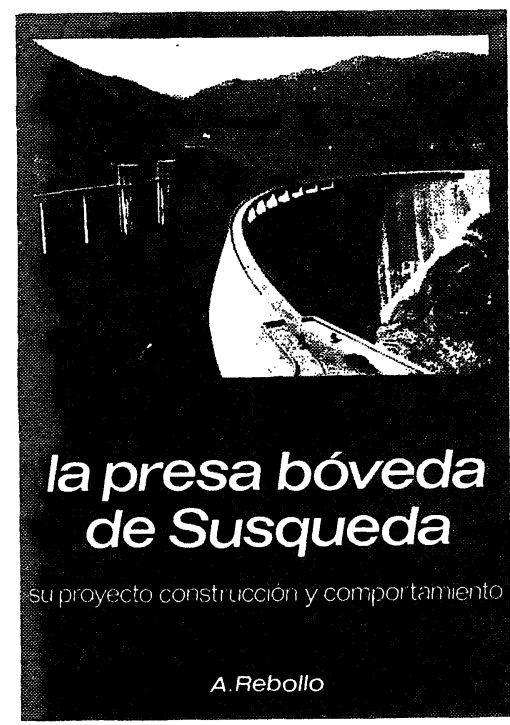

La presa bóveda de Susqueda

A. Rebollo,

Dr. Ingeniero de Caminos

El esfuerzo del constructor de presas se sitúa por su pretensión de perennidad, a contracorriente de lendencias de la civilización actual, caracterizada por to fungible. Pueden evocarse las 10.000 grandes presas en funcionamiento o en construcción que están envejeciendo $y$ reclaman los cuidados gerontológicos para mantener y perfeccionar su servicio y garantizar su inalienable pretensión de perennidad. En la medida en que todas nuevas obras, grandes o pequeñas, son portadoras de riesgos ecológicos $y$ a veces, catastróficos, que aumentan con el envejecimiento, la gerontologia de las presas es todo un emplazo. La acción adelantada de Arturo Rebollo en este terreno marca un camino a seguir para todos los que aman su propia obra con la devoción paternal que èl ha puesto en Susqueda.

Un volumen encuadernado en cartoné plastificado con lomo de tela, de $18 \times 24,5 \mathrm{~cm}$, compuesto de 408 páginas, 330 figuras $y$ fotografias $y 39$ tablas.

Precios: 1.700 ptas.; extranjero, \$ USA 24.00. 